\title{
Two Sides of the Same Coin: U.S. "Residual" Inequality and the Gender Gap*
}

\author{
Marigee Bacolod \\ Bernardo S. Blum ${ }^{\dagger}$ \\ University of California-Irvine University of Toronto
}

January 17,2005

\begin{abstract}
In this paper we show that the two major developments experienced by the US labor market - rising inequality and narrowing of the male-female wage gap - can be explained by a common source: the increase in price of cognitive skills and the decrease in price of motor skills. We obtain the price of a multidimensional vector of skills by combining a hedonic price framework with data on the skill requirements of jobs from the Dictionary of Occupational Titles (DOT) and workers' wages from the CPS. We find that in the 1968-1990 period the returns to cognitive skills increased 4-fold and the returns to motor skills declined by $30 \%$. Given that the top of the wage distribution of college and high school graduates is relatively well endowed with cognitive skills, these changes in skill prices explain up to $40 \%$ of the rise in inequality among college graduates and about $20 \%$ among high school graduates. In a similar way, because women were in occupations intensive in cognitive skills while men were in motor-intensive occupations, these skill price changes explain over $80 \%$ of the observed narrowing of the male-female wage gap.
\end{abstract}

\footnotetext{
*The authors are grateful to Dan Trefler, Joe Hotz, Ig Horstmann, David Neumark, Ken Sokoloff, Paul Devereux, Jun Ishii, Dan Bogart, and Flavio Cunha for insightful and thoughtful comments. We also thank participants of the Trade Seminar at the University of Toronto and the Junior Lunch Seminar at UC Irvine.

${ }^{\dagger}$ Please address correspondence to bblum@rotman.utoronto.ca and mbacolod@uci.edu.
} 


\section{Introduction}

The U.S. labor market since 1970 has been characterized by two major developments: a dramatic rise in income and wage inequality and a narrowing of the male-female wage gap. An important literature has sprung up investigating the degree to which these two phenomena can be attributed to changes in the returns to skills. ${ }^{1}$ While increasing returns to skills can help explain the rise in wage inequality, current studies also suggest that increasing returns to skills should widen the gender wage gap, a conclusion at odds with the data. ${ }^{2}$

In this paper, we find that changes in returns to skills can in fact help explain both phenomena if skills are measured multidimensionally. If the returns to one skill (e.g., cognitive skills) rise much faster than another (e.g., motor skills), we would expect a widening gap in the wages between workers in cognitive-intensive and motor-intensive occupations, even within education groups. Furthermore, if female workers are disproportionately in relatively more cognitive-intensive occupations (as compared to male workers), then this shift in relative returns to skills would also narrow the gender wage gap. Therefore, changes in relative returns to skills can drive both increasing "residual" income inequality - the rise in wage inequality not accounted for by observable characteristics - and the narrowing of the gender wage gap.

We provide empirical evidence supporting this conjecture. By applying a hedonic framework to an integrated data set that matches workers' wages to job-specific skill demands, we estimate the change in relative returns to skills from 1968 to 1990. The wage data is obtained from the Current Population Survey (CPS) while the skill description of occupations are derived from the Dictionary of Occupational Titles (DOT).

\footnotetext{
${ }^{1}$ See for example Bound and Johnson (1992), Ingram and Neumann (2005), Juhn Murphy and Pierce (1993), Katz and Murphy (1992), Levy and Murnane (1992), and Katz and Autor (1999) for careful documentation of increased inequality and rising returns to skills. Altonji and Blank (1999) survey the literature on the gender gap.

${ }^{2}$ See for example Blau and Kahn (1997). Mulligan and Rubinstein (2004) try to reconcile these two facts by arguing that, once controlling for women self-selection in the decision to work, there was no actual convergence of the gender gap. Our findings are different, as we discuss in the conclusion.
} 
We find that increased inequality was not associated with a general increase in the returns to all types of labor market skills. Our findings show that the price of cognitive skills increased 4-fold while the price of motor skills decreased by $30 \%$ between 1970 and $1990 .{ }^{3}$ At the same time, we find that women are increasingly located in occupations relatively more intensive in cognitive skills while men are in occupations relatively more intensive in motor skills. In 1970, college graduate females were, on average, in occupations $7 \%$ less intensive in cognitive skills than college graduate males. However, by 1980, college graduate females were on average in occupations $1 \%$ more cognitive intensive than their male counterparts. This allowed women to be better positioned than men to benefit from the rise in the relative price of cognitive skills throughout the 1980s.

We show that these two results help explain much of the "residual" wage inequality and narrowing of the gender wage gap observed in the post-1970 U.S. labor market. Applying the framework developed by Juhn, Murphy, and Pierce (1993), we find that changes in skill prices account for up to $40 \%$ of the rise in inequality among college graduates and up to $20 \%$ of increased inequality among high school graduates. In the 1980 s, when most of the narrowing of the gender wage gap occurred, we find that about $90 \%$ of the observed narrowing is explained by changes in skill prices and only about $10 \%$ is explained by labor force compositional changes.

The remainder of the paper is organized as follows. The next section presents a hedonic price framework linking skills to wages, which will be used to back out implicit prices of skills. Section 3 describes the datasets used in the analysis, paying detailed attention to the Dictionary of Occupational Titles. Section 4 discusses the empirical strategies, and section 5 shows the prices of cognitive skills, motor skills, people skills, and strength in the US labor market. Section 6 analyzes how much of residual inequality is due to the estimated changes in skill prices, and section 7 analyzes how much of the narrowing of the male-female wage gap can be accounted by the skill price changes. The final section concludes.

\footnotetext{
${ }^{3}$ We also find the hedonic price of people skills decreased, particularly for college graduates, while the price of strength did not change significantly over this period.
} 


\section{A Hedonic Price Model of the Labor Market}

The notions that workers with different skills are matched to jobs requiring different skills and that the labor market earnings of individuals can be decomposed into payments to productive attributes have been around at least since the work of Roy (1950), Tinbergen (1951, 1956, and 1959), and Mandelbrot (1962). In this section we develop a simple version of these models to illustrate the way in which implicit prices of skills can be backed out from wages and from worker, occupation, and firm characteristics. The main characteristic of the model is that there is a continuum of occupations such that workers can always find one where their vector of skills are fully employed. ${ }^{4}$ The purpose of the model is to make explicit the logic behind the empirical work developed later in the paper as well as to highlight the main underlying assumptions.

Suppose firms combine different occupations in order to produce final products. Each occupation $J$ is defined as a vector of skills $\mathbf{z}_{j}$ required to perform the occupation. Let the function $w\left(\mathbf{z}_{j}\right)$ give the wage associated with each occupation $\mathbf{z}_{j}$. Given technologies and the distribution of firms in the economy, there is a derived demand function for occupation $J$ that depends on wages. Let $D_{j}\left(\mathbf{w}(\mathbf{z}) ; x_{d}\right)$ represent such a derived demand, where $x_{d}$ represents anything that might shift the demand function, such as technological change or change in the distribution of firms in the economy.

On the other side of the labor market, suppose that each worker is endowed with one unit of labor specific to one occupation. Suppose also that workers of type $J$ supply labor in occupation $J$ and that there is a given distribution of worker types. ${ }^{5}$ Let $S_{j}\left(x_{s}\right)$ represent the supply of workers in occupation $J$, and let $x_{s}$ represent supply shifters. For example, these might include changes in demographics or cohort effects.

The equilibrium in the labor market is defined by the existence of a wage function $w(\mathbf{z})$

\footnotetext{
${ }^{4}$ An alternative way of stating this is that bundling constraints are not binding. On the importance of bundling, see Heckman and Scheinkman (1987). The formulation used here is standard in the Industrial Organization literature; see for example Rosen (1974) and Epple (1987).

${ }^{5}$ Allowing workers to choose in which occupation to supply labor can be added to the framework without any significant complication. See Rosen (1974) and Epple (1987) for examples.
} 
that clears the market for all occupations: $D_{j}\left(\mathbf{w}(\mathbf{z}) ; x_{d}\right)=S_{j}\left(x_{s}\right)$. Such an equilibrium wage function can be obtained algebraically from the following set of partial differential equations: ${ }^{6}$

$$
\sum_{k}\left\{\frac{\partial D_{j}}{\partial w\left(\mathbf{z}_{k}\right)}\left[\sum_{i} \frac{\partial w\left(\mathbf{z}_{k}\right)}{\partial z^{i}}\right]\right\}=\sum_{i} \frac{\partial S_{j}}{\partial z^{i}} \quad \forall j
$$

where $z^{i}$ represents the $i^{\text {th }}$ element of vector $\mathbf{z}$. An important assumption made here is that a sufficiently large number of occupations are available such that effectively the demand for different combinations of skills is continuous for all purposes. The adequacy of this assumption for the labor market can be questioned. However, as discussed in the empirical section, the dataset we use contains information on over 12,000 finely defined occupations, so this assumption may be a reasonable approximation in this case. ${ }^{7}$

From the wage function

$$
w_{j}=w\left(\mathbf{z}_{j}\right)
$$

we can determine the implicit price of skills. The implicit price of skill $z^{i}$ is given as:

$$
q_{i}=\frac{\partial w(\mathbf{z})}{\partial z^{i}}
$$

In general there are no closed-form solutions for equations 1 and $2 .{ }^{8}$ The usual empirical strategy is to estimate the hedonic price equation (1) using the functional form that best fits the data and then obtain the implicit prices of skills using equation 2. This is the strategy we pursue in the empirical section of the paper.

\footnotetext{
${ }^{6}$ Solutions for specific cases can be found in Rosen (1974), Sattinger (1980), and Epple (1987), and many others.

${ }^{7}$ In case we assume a finite number of occupations the model developed here collapses back to the Roy model. However, estimating the Roy model with the large number of occupations we have in the data would not be computationally feasible (see Dahl (2002). Moreover, as we discuss in the conclusion, the use of the Roy model can only enforce the results we find in the empirical section.

${ }^{8}$ One exception is when the cost function (and possibly the utility function) is assumed to be quadratic, and firms and consumers are normally distributed. In this case the wage function can be shown to be quadratic in workers' characteristics and prices of skills are linear in characteristics. See Epple (1987).
} 


\section{Data}

\subsection{Dictionary of Occupational Titles (DOT)}

For fine measures of tasks performed in particular jobs, we turn to the Fourth Edition of the Dictionary of Occupation Titles (DOT). The DOT was first developed in response to the demand of an expanding public employment service for standardized occupational information to support job placement activities. The U.S. Employment Service recognized this need in the mid-1930s, soon after the passage of the Wagner-Peyser Act established a federal-state employment service system. The use of DOT information mainly has been for job matching applications, employment counseling, occupational and career guidance, and labor market information services. A few economists also have used the information in DOT, most notably, Autor et al. (2003), Wolff (2000, 2003), and Ingram and Neumann (2005).

The first edition of DOT was published in 1939, and it was subsequently updated in 1949, 1965, 1977, and 1991. The period our study covers coincides very well with information from the 1977 Fourth Edition and the 1991 Revised Fourth Edition. Information in the 1977 Fourth Edition were collected between 1966 and 1976, while data in the 1991 revision were collected between 1978 and 1990. Thus, DOT skill measures from the 1977 Fourth Edition describe occupations in the 1970s, while occupations in the 1980s are best described by the 1991 revised Fourth Edition. The revised Fourth Edition actually updated 2453 occupations out of a total of $12,742 .{ }^{9}$

Occupational definitions in DOT are the result of comprehensive studies by trained occupational analysts of how jobs are performed in establishments across the nation and

\footnotetext{
${ }^{9}$ The first edition of DOT issued in 1939 contained approximately 17,500 concise occupation definitions and indicated whether the jobs were skilled, semi-skilled, or unskilled. The second edition of DOT, issued in March 1949, combined material from the first edition with several supplements issued throughout the World War II period. The third edition of DOT, issued in 1965, eliminated the previous designation of a portion of the occupations as "skilled, semi-skilled, or unskilled" and substituted a classification system based on the nature of the work performed and the demands of such activities upon the workers. After the last revision in 1991, it has been replaced by $\mathrm{O}^{*} \mathrm{NET}$, an online database.
} 
are composites of data collected from diverse sources. ${ }^{10}$ Given DOT's original purpose of evaluating the fit between workers and occupations, many of the DOT variables are expressed in terms of necessary or desirable personality characteristics (i.e., temperament and interests) of the worker. Information on necessary or desired skill levels in a variety of areas (physical demands, job complexity in relation to data, and people) were also collected. Therefore, DOT characteristics from the 1977 and 1991 editions describe in great detail the skill levels required to perform each occupation during the late 1960s, 1970s, and through the 1980s.

\subsubsection{Selecting DOT Task Measures: Constructing Skill Measures}

There are 44 different job characteristics available in the fourth edition DOT published in 1977 and in its revision published in 1991. These fall into seven clusters: work functions; required General Educational Development (GED); aptitudes needed; temperaments needed; interests; physical demands; and working conditions in the environment. All these variables were first re-scaled so that higher values denote higher requirements.

Our first objective is to identify a plausible subset of these 44 DOT task measures and then to generate interpretable summary measures of occupational skill requirements. Using the textual definitions of the variables, we identify four broad skill categories in the DOT data. ${ }^{11}$ These are: cognitive skills, motor skills, physical demands, and people skills. While we can generate skill measures from a joint factor analysis of the 44 DOT variables, an undesirable consequence of this procedure is that skill indices are orthogonal to each other by construction. That would prevent us from speaking about possible skill complementarities that, as will be clear later, are a key aspect of the data. To allow for skill complementarities we construct our skill indices based on textual definitions.

Although many variables in the DOT dataset capture different dimensions of cognitive

\footnotetext{
${ }^{10}$ For instance, more than 75,000 on-site job analyses were conducted for the Fourth edition of DOT; for jobs difficult to observe, information was obtained from professional and trade associations. See Miller et al (1980) for a more complete description of the procedures used to produce the Fourth edition of DOT.

${ }^{11}$ These categories or similar ones have been previously explored in the literature using the 1977 Fourth Edition DOT. See Miller et al. (1980), Wolff (2000, 2003), and Ingram and Neumann (2005).
} 
skills required to perform a job, no single one of them seems to be able to fully capture the substantive complexity or cognitive demands of an occupation. High collinearity among the variables prevents us from using all or even many of them at the same time. We therefore construct a cognitive index through factor analysis of seven DOT "cognitive" variables: complexity of the job in relation to data; GED in reasoning, mathematics and language for the job; and aptitudes for intelligence, verbal, and numeric. These variables are further described in Table 16 in the appendices. Panel A of Table 10, also in the appendix, reports results for our principal components analysis to generate this cognitive index from the 1977 DOT and the 1991 DOT. The first factor explains 99.32\% (1977 DOT) and 100\% (1991 DOT) of the variation in these seven variables, while each DOT variable loads about equally, with loadings ranging from 0.83 to 0.95 .

A higher value on this cognitive index indicates that substantive complexity is involved in carrying out the job. For instance, gedm measures mathematical development required for the job. At high gedm levels, workers are required to know advanced calculus, while at low levels, they are required only to know how to perform arithmetic.

Analogous to our measure of cognitive skills, no single variable in the DOT dataset is able to capture the different dimensions of the fine motor skill requirements of an occupation. We construct a motor skills index from nine DOT variables: complexity of the job in relation to things; aptitudes for manual dexterity, finger dexterity, motor coordination, eye-hand-foot coordination, spatial and form perception, and color discrimination; and adaptability to situations requiring attainment of standards. These variables also are described further in Table 16. Panel B of Table 10 in the appendix shows that the first factor explains $84.51 \%$ (1977 DOT) and 95.38\% (1991 DOT) of the variation on these nine variables.

A higher value on the motor skills index indicates a job with greater manual demands. High complexity of the job in relation to things indicates that workers are required to set up and adjust machinery and to work it precisely. Lower values are assigned to jobs where workers have little or no involvement in selecting appropriate tools or in attainment of standards. 
The physical demand of jobs is measured by the variable "strength." The DOT defines this variable as the degree of strength requirements of job as measured by involvement in standing, walking, sitting, lifting, carrying: from very heavy, heavy, medium, to light, sedentary. Lower values of an index generated from this factor thus indicate a relatively sedentary occupation.

Finally, we measure the interpersonal skill requirements of jobs. For that, we use the variable "people." This variable is defined as the complexity at which worker performs job in relation to people, from highest to lowest: mentoring; negotiating; instructing; supervising; diverting; persuading; speaking-signaling; serving; taking instructions.

After generating factor scores for cognitive and motor skills, we re-scale each of them to have a mean of 100 and a standard deviation of 10. For comparability, we also re-scale the variables "people" and "strength" to have mean 100 and standard deviation of 10.

It should be noticed that large amounts of sensitivity analysis regarding the way these skills are measured have been conducted and are reported in the appendices. The bottom line is that the main results discussed below are extremely robust.

\subsection{Current Population Survey}

Our wage and employment data come from the March Current Population Surveys (CPS) 1968-1990. ${ }^{12}$ Although the CPS is available prior to 1968, the census occupation and industry codes for these years are too coarse for our purposes. Our sample includes employed individuals aged 18-64 who were not living in group quarters, were not in school, were not working without pay, had a positive number of years of potential labor market experience, had non-missing occupational responses, and had earned at least three full-time months of minimum wage or above that year. We also impute earnings for workers top-coded by the census as 1.5 times the top-code value. All wages are deflated by the CPI for All Urban Consumers, with base year 1982-84. ${ }^{13}$ The results reported below are not qualitatively

\footnotetext{
${ }^{12}$ Source: CPS Utilities, Unicon Research Corporation.

${ }^{13}$ Source: Bureau of Labor Statistics.
} 
sensitive to the imputation outlined and to the wage measure used (weekly versus annual earnings). We report results below using weekly earnings.

We match DOT job skills from the 1977 Fourth Edition to workers in the March CPS surveys from 1968 to 1977. For workers in the March CPS 1978-1990, their DOT job skills come from the 1991 revised Fourth Edition. As noted above, both the 1977 and 1991 DOT scored more than 12,000 occupations. However, as with most surveys, the CPS does not code to such a detailed occupational classification as DOT (about only 450). To map DOT codes to census occupation codes, we utilize a special version of the April 1971 CPS issued by the National Academy of Sciences (2001), in which a committee of experts assigned individual DOT occupation codes and measures to the 60,441 workers in that sample. To convert this special CPS sample into DOT skill measures by census cells, we calculate weighted means (using CPS sampling weights) of DOT skill indices by census occupation within census industry and separately by gender. ${ }^{14}$

Finally, to merge these DOT means to each worker's job in the CPS, we create a uniform occupation coding scheme across CPS years 1968-1990. The 1\% census samples (IPUMS) have such a scheme, where 1960, 1970, 1980, and 1990 census occupation and industry codes are mapped to 1950 definitions (variables occ1950 and ind1950). We utilize this uniform occupation classification scheme to merge DOT means to CPS workers.

Autor, Levy, and Murnane (2002) develop their own census occupation code crosswalk over time, and they have kindly provided this crosswalk to us. Preliminary checks indicate our crosswalk and their crosswalk leads to about the same results. We end up losing a number of observations utilizing the Autor et. al. crosswalk, however, so the results below are using the IPUMS crosswalk.

\footnotetext{
${ }^{14}$ More than $90 \%$ of all observations in the 1968-1990 March CPS are matched at this level of aggregation. For the remaining unmatched observations, we merge DOT indices to the CPS at the census occupation level by gender, leaving less than 1\% (CPS years 1968-1977) and 2\% (1978-1990) unmatched. We merge DOT indices at the census occupation level to these remaining observations and exclude unmatched observations due to missing occupation codes $(0.3 \%)$.
} 
Table 1:

Top and Bottom 10 Occupations in the Skill Distribution, DOT

\begin{tabular}{cccc}
\hline \multicolumn{2}{c}{ Cognitive Skills } & \multicolumn{2}{c}{ Motor Skills } \\
Bottom 10 & Top 10 & Bottom 10 & Top 10 \\
\hline Laundresses & Geologists & Bill collectors & Physicians \\
Oilers & Physicists & Crossing watchmen & Artists \\
Cleaners & Chemists & Lawyers & Veterinarians \\
Laundry operatives & Mathematicians & Social workers & Machinists \\
Fruit packers & Engineers & Clergymen & Draftsmen \\
Stevedores & Physicians & Credit men & Toolmakers \\
Telegraph messengers & College professors & Religious workers & Jewelers \\
Lumbermen & Lawyers & Boarding keepers & Technicians \\
Teamsters & Scientists & Authors & Engravers \\
Ushers & Architects & Agents & Mechanics \\
\hline \hline Physical Demand & & People Skills \\
Bottom 10 & Top 10 & Bottom 10 & Top 10 \\
\hline Authors & Firemen & Cabinetmakers & Clergymen \\
Mathematicians & Stevedores & Plumbers & Lawyers \\
Scientists & Mine operatives & Lumber inspectors & Religious workers \\
Optometrists & Plumbers & Millers feed & Physicians \\
Reporters & Millwrights & Bookbinders & Social workers \\
Lawyers & Plasterers & Meat cutters & Psychologists \\
Statisticians & Farmers & Machinists & Economics professors \\
Secretaries & Sailors & Engravers & College professors \\
Credit men & Mechanics & Bricklayers & K-12 teachers \\
Bookkeepers & Metal workers & Roofers and slaters & Sports officials \\
\hline \hline
\end{tabular}

\subsection{Descriptive Analysis}

Table 1 lists the top and bottom 10 occupations in each of our skill measures, and confirms that the DOT dataset does a sensible job classifying the skill requirements of occupations.

By and large, occupations in the bottom of the cognitive index distribution are dominated by operatives, non-private household service workers, and laborers. Laborers include stevedores and lumbermen, operatives include oilers and greasers, drivers, and welders, and non-household service workers include waiters and beauticians. Meanwhile, the top of the cognitive index is primarily comprised of professional workers, including college professors, 
scientists, managers, officials, and proprietors.

The motor skills index points to finer motor skills associated with the job. Occupations in the top of the motor skill index distribution are dominated by craftspeople, draftspeople, and technicians (e.g., medical and dental), including machinists. These are all occupations where individuals need high levels of motor coordination and finger dexterity. At the bottom of the motor distribution we find lawyers, social and sales workers, and clergy.

As one expects, craftspeople and operatives are also in physically demanding occupations, as are firefighters, farm workers, and stevedores. The less physically demanding jobs include scientists, secretaries, bookkeepers, and lawyers. Finally the occupations demanding the most "people" skills are lawyers, therapists, teachers, and clergy, among others.

One might argue that these skill indices are merely proxies for occupation dummies. In fact, regressions of our skill measures on more than 200 census occupation dummies reveal they are positively correlated, with adjusted R-squareds ranging from 0.51 to 0.7 . They are not perfectly correlated, however. Our skill measures are an improvement upon analyses that control for occupation dummies in that they are interpretable. While occupation dummies would certainly absorb more of the across-occupation variation in wages, our skill indices from the DOT characterize these occupations with an interpretable four dimensional vector of skills.

Table 2 reports means of DOT skill indices by educational level for selected CPS years. As expected, individuals with higher levels of education are in occupations requiring greater cognitive and people skills and are in jobs that are less physically demanding. For instance, college graduates are in occupations with an average cognitive skill index of 109, while high school graduates' jobs require only 99 on average, followed by 94 in jobs occupied by those without a high school degree in 1970.

Meanwhile, those without a high school degree are in jobs with the greatest physical demands, with an average index of 106, followed by high school graduates at 100, and by college graduates only at 96 in 1970. College graduate workers are also in occupations that require slightly less motor skills than high school graduates. These differences in the 
various skill requirements across education groups are statistically significant. It is also worth noting that skill requirements appear to be stable over time, even within education groups.

Tables 1 and 2 display the correlation among the skill requirements of occupations in the 1977 and 1991 DOT data. Occupations that require more cognitive skills tend also to require more people skills over the entire period. Occupations that require less cognitive or people skills tend to require more strength and, to a lesser extent, more motor skills. While motor skills and strength are positively correlated at 0.2 to 0.3 , cognitive and people skills seem to be even more complementary, being correlated at 0.6. Table 3 suggests that skill requirements may significantly interact in the performance of job-specific tasks and that accounting for skill complementarities may be important in understanding changes in the overall wage distribution.

Another important finding from Table 3 is the increased correlation between cognitive and motor skills between the 1970s and 1980s. The raw correlation suggests this went up four-fold. Given what motor skills measure, the increased complementarity in cognitive and motor skill requirements may in part be due to increased computerization in the workplace. Finally, we note that none of the skill correlations are high enough to cause concern about multicollinearity issues.

\section{Empirical Specification and Issues}

The empirical counterpart of equation 1 is estimated using the following specification:

$$
\ln w_{i k t}=\gamma_{t}^{\prime} z_{k t}+X_{i t}^{\prime} \beta_{t}+\varepsilon_{i t}
$$

where $w_{i k t}$ is the annualized wage earnings of individual $i$ in occupation $k$ at time $t$, and $X_{i t}$ includes individual characteristics such as age, age-squared, gender, race, education level, SMSA status of residence, as well as year and region fixed effects. The vector $z_{k t}$ denotes 
the DOT characteristics required to perform occupation $k$ and proxy for the workers' skills in that occupation. In order to account for the possible skill complementarities suggested by Table 3, the vector $z_{k t}$ includes interactions between skill measures and possibly quadratic terms as well. ${ }^{15}$ The vector $\mathbf{q}_{\mathbf{t}}=\gamma_{\mathbf{t}} * w_{t}$ then forms our hedonic price estimates of various skills required to perform an occupation.

In addition, we examine whether skill prices vary across education groups by estimating

$$
\ln w_{i k t}=\gamma_{j t}^{\prime}\left(d_{j} \otimes z_{k t}\right)+X_{i t}^{\prime} \beta_{t}+\varepsilon_{i t}
$$

where $d_{j}$ denotes a dummy-variable vector indicating person $i$ 's education level. Skill prices are now estimated separately for each education group $j$ : less than high school, high school graduate, and college graduate.

In practice, equations 3 and 4 are estimated separately by year, so the year dummy is essentially the intercept or constant. It should be noted that the source of variation identifying $\beta_{t}$ and $\gamma_{j t}$ are the differences in wages and skill requirements across occupations at a given point in time. Estimated standard errors allow for non-zero covariance across workers in the same occupation, industry, and year.

There are three estimation issues that deserve attention, two of them that may affect the consistency of our estimates of $\gamma_{t}$ and $\gamma_{j t}$. First, our skill variables are potentially measured with error given we do not know exactly the year in which the skills required to perform a given job changed during the 1968-1991 period. All we know is that it changed and the old and new requirements. For the 1968-1977 period, we use the skill requirements from the DOT Fourth Edition published in 1977, with data collected between 1967 and 1977. For the 1978-1991, period we use data from the 1991 revision to the Fourth Edition, with data collected form 1978 to 1990. Within these two sub-periods of the sample, the skill requirements are assumed to be unchanged. ${ }^{16}$ This can potentially bias our

\footnotetext{
${ }^{15}$ The specification we estimate is similar to others in the literature explaining wage inequality (e.g., Borjas and Ramey (1995) and Juhn, Murphy, and Pierce (1993) except that we measure task requirements and not just educational attainment, experience, or blue- versus white-collar jobs.

${ }^{16}$ Changes over time in skill requirements are studied in a different paper where we look for evidence of
} 
estimates if mismeasurement is systematically correlated with the observed skills. To deal with this, in appendix A.2, we re-estimate our models for a sub-sample of occupations whose skill requirements did not change between the 1977 edition and its 1991 revision. When restricting our analysis to occupations that were not revised, our results are highly robust, both qualitatively and quantitatively. This suggests that measurement errors arising from this issue are not biasing the results presented below in a significant way.

Secondly, because the DOT skill measures are occupation specific, they are at best proxies rather than exact measures of individual workers' skills. In principle it is possible for a worker at a given occupation to have more skills than what is required to perform that occupation. ${ }^{17}$ Let the vector of skills of worker $i$ in occupation $k\left(z_{i k t}^{*}\right)$ be equal to the skill requirement stated by the DOT $\left(z_{k t}\right)$ data plus an error term:

$$
z_{i k t}^{*}=z_{k t}+v_{i k t}
$$

As long as the "measurement error" $v_{i k t}$ above is uncorrelated with measured skills $\left(\operatorname{Cov}\left(z_{k t}, v_{i k t}\right)=0\right)$, the skill price estimates from equations 3 and 4 will be consistent. However, if workers in occupations requiring more of a given skill tend to have higher-thanrequired amounts of that skill but for workers in occupations requiring less of that skill that is not the case $\left(\operatorname{Cov}\left(z_{k t}, v_{i k t}\right)>0\right)$, then estimates of $\gamma_{t}$ and $\gamma_{j t}$ will be biased upward.

For the purposes of this paper, our main interest is in how skill prices $\left(\gamma_{t}\right.$ and $\left.\gamma_{j t}\right)$ changed over time. Even if $\operatorname{Cov}\left(z_{k t}, v_{i k t}\right) \neq 0$, as long as these covariances are not changing systematically over time, the estimates from equations 3 and 4 will still appropriately capture the over-time changes in the skill prices. Furthermore, it should be stressed that there is no direct interpretation of the level or point estimates of $\gamma_{t}$ and $\gamma_{j t}$, whether biased or unbiased. Given our skill indices are generated from factor analysis, our estimates of skill prices to begin with are identified only up to a constant.

The third issue is that the log-linear functional form employed generates skill prices skill-biased technological change in the 1977-1991 period.

${ }^{17}$ Notice that this would not be a problem if such excess skill is not rewarded. 
that depend on the average wages, as given by the expression $\mathbf{q}_{\mathbf{t}}=\gamma_{\mathbf{t}} * w_{t}$. Because of this, changes in skill prices over time may be a consequence of changes in average real wages and not of changes in the marginal contribution of skills to wages. In order to deal with this, in appendix A.3 we estimate a log-log specification and show unit free skill elasticities of wages. The results indicate that the over time changes discussed below are not merely due to changes in average real wage. The elasticity of wages with respect to cognitive skills increased from 0.30 in the $1968-1970$ period to 1.6 in the $1988-1990$ period. Meanwhile, the elasticity of wages with respect to motor skills decreased from 0.85 to 0.55 over the same period.

\section{$5 \quad$ Skill Prices in the US Economy}

In this section we present estimates of skill prices in the US labor market in the 1968-1990 period. In the next two sections, we provide an account of how much of the observed rise in residual inequality and of the observed narrowing of male-female wage gap is due to the estimated changes in skill prices. To briefly summarize, we find that (a) the 1968-1990 period witnessed a large increase in the value of cognitive skills and a large drop in the value of motor skills; (b) because even within education groups the top of the wage distribution is relatively well endowed in cognitive skills, the changes in skill prices are responsible for up to $40 \%$ of the observed rise in residual inequality for college graduates, for example; and (c) because females moved into jobs intensive in cognitive skills relative to motor skills while males did the opposite, the changes in skill prices are responsible for up to $90 \%$ of the observed narrowing of the male-female wage gap.

Estimates of equation 3 are shown in appendix Table 17 for selected years. ${ }^{18}$ From the parameters shown in this table the values of skills are obtained.

\footnotetext{
${ }^{18}$ The patterns displayed here are confirmed throughout the period. The entire set of parameter estimates when these are allowed to vary across education groups is shown in the appendix Table 18.
} 


\subsection{The Price of Cognitive Skills}

The value of cognitive skills can be computed from the parameter estimates presented in table 17 as:

$$
\frac{\partial w}{\partial(\operatorname{Cog})}=\bar{w} \frac{\partial \log w}{\partial C o g}=\bar{w}\left(\beta_{1}+\delta_{1} M_{o t}+\delta_{2} P h y_{i}+\delta_{3} P e o\right)
$$

Figure 1 shows the value of cognitive skills along with two-standard deviation bands over time. ${ }^{19}$ The first row in Table 4 reports 3-year moving averages of the value of these skills for selected years.

Cognitive skills are positively and significantly valued in the US labor market throughout the period. The value of cognitive skills has increased dramatically since the beginning of the 1970s at an annual growth rate of $19 \% .^{20}$ In contrast to the observed rise in the education premium, which happened only towards the end of the 1970s, the rise in prices of cognitive skills started at the end of the 1960s and accelerated at the beginning of the 1970s. As an example, in 1970 a change in occupation associated with a one standard deviation increase in cognitive skill requirements, such as going from having the cognitive skills required to be a carpenter or car mechanic to having the cognitive skills required to be a draftsperson or designer, was associated with a $5.2 \%$ increase in wages. By 1975, this was associated with $9 \%$ higher wage. Such a skill premium stayed close to constant until 1982 and then steadily increased. By 1985, the same one standard deviation change in skill requirements was associated with a $13.5 \%$ increase in wages and by 1990, a $16 \%$ higher wage.

In addition, cognitive skills are valued differently for different education groups. The first part of Table 5 shows the value of cognitive skills when estimated separately for college, high school, and less than high school graduates. It shows that cognitive skills are valued for high school and college graduates but not significantly for workers with less than a

\footnotetext{
${ }^{19}$ The average real wage in the CPS sample is used as $\bar{w}$. Whenever skill prices are computed by education group, $\bar{w}$ is calculated as the average real wage by education group in the CPS sample.

${ }^{20}$ Tests reveal this rising trend is significantly different from 0 .
} 
Figure 1: Price of Cognitive Skills.

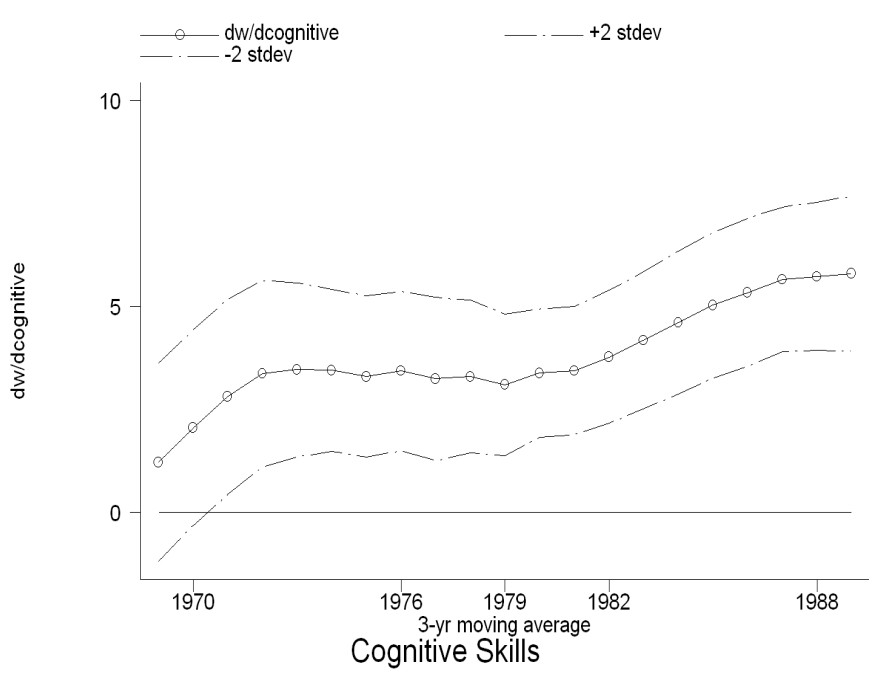

high school diploma. While the price of cognitive skills increased across education groups, the increase has been greater among college graduates than those with less than college. Cognitive skills were rewarded about 2 times more for college graduates than to high school graduates in 1970 and, by 1990, they were more than 3 times more valuable. Figure 2 shows the value of cognitive skills by educational groups over time.

\subsection{The Price of Motor Skills}

The value of motor skills can be calculated in a similar way. Figure 3 shows the value of motor skills over time, and the second row in Table 4 displays moving averages of these values for selected years.

Motor skills are also positively and significantly valued throughout the period. As opposed to what happened to cognitive skills, motor skills became significantly less valuable during the 1968-1990 period, at an annual rate of $5.6 \% .^{21}$ In 1970 , a change in occupation that implied a one standard deviation increase in motor skill requirements, equivalent to going from the motor skills of an economist or a psychologist to the motor skills of a

\footnotetext{
${ }^{21}$ Tests reveal this declining trend is significantly different from zero.
} 
Figure 2: Price of Cognitive Skills by Educational Group.

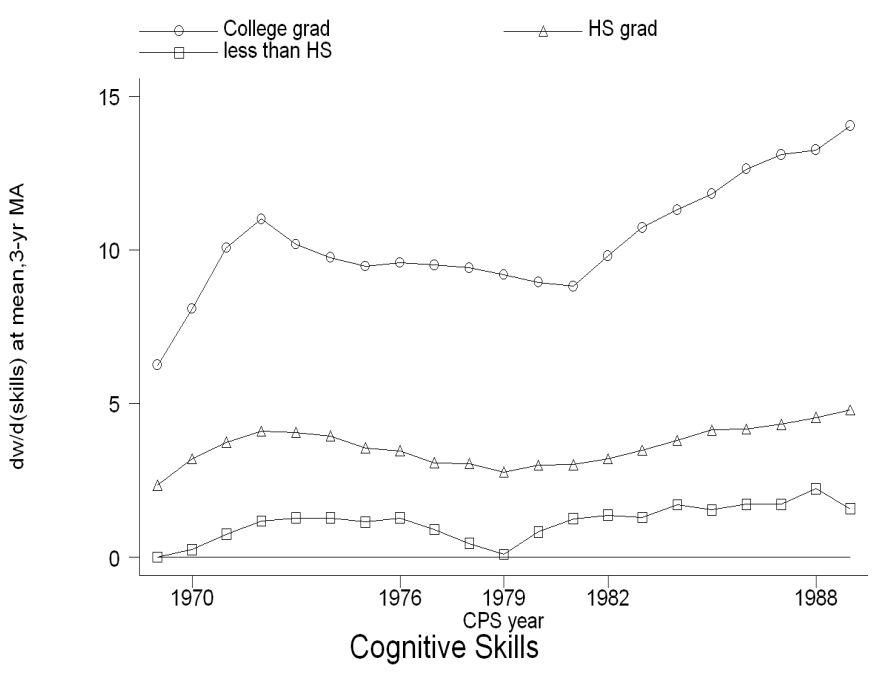

metallurgical engineer, was associated with an $8 \%$ rise in wages. The value of motor skills fell over this period and, by 1990, the same occupational change was associated with only a $5 \%$ wage differential.

Just as with cognitive skills, motor skills are valued differently by different education groups, as shown in Figure 4 and in the second part of Table 5. Again, motor and cognitive skills behave very differently. Motor skills are significantly valued by high school graduates and less but not by college graduates. Throughout the period, motor skills were about $70 \%$ more valuable to workers with less than a high school degree than to high school graduates. For both of these groups, the value of motor skills decreased steadily over the period at approximately the same rate.

\subsection{The Price of Strength and People Skills}

The values of strength and people skills are calculated in similar ways. These two sets of skills are rewarded in the labor market mainly through their complementarity with cognitive or motor skills, as shown in Table ??. In occupations that demand strength, cognitive and people skills tend to be less valuable, and in occupations that demand people skills, strength 
Figure 3: Price of Motor Skills.

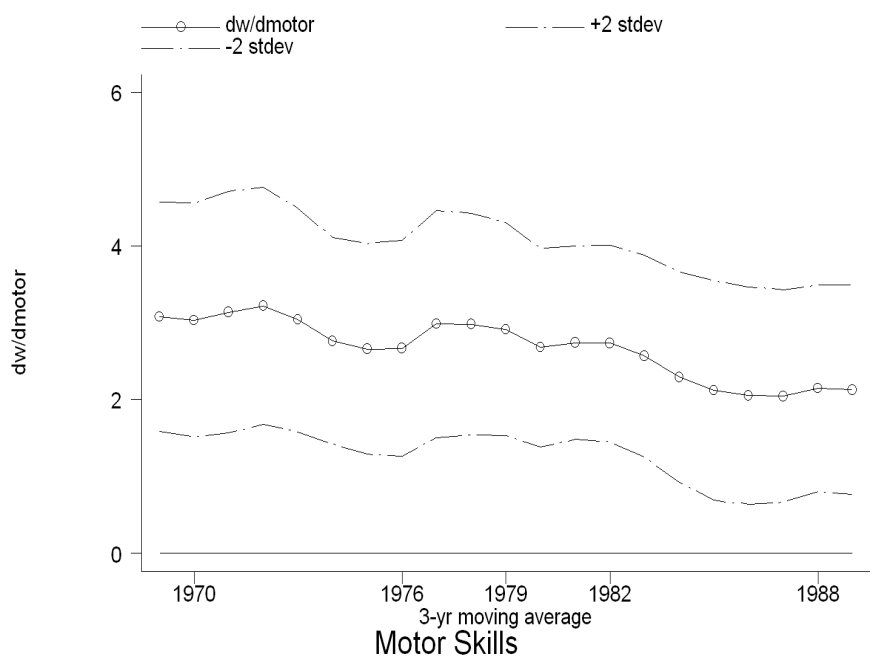

Figure 4: Price of Motor Skills by educational Groups.

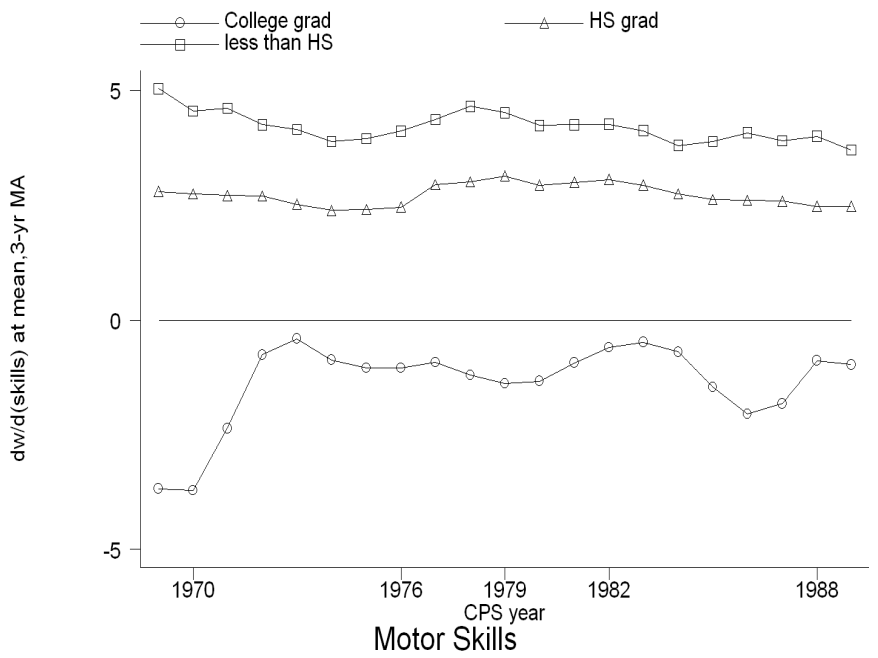


Figure 5: Price of Strength.

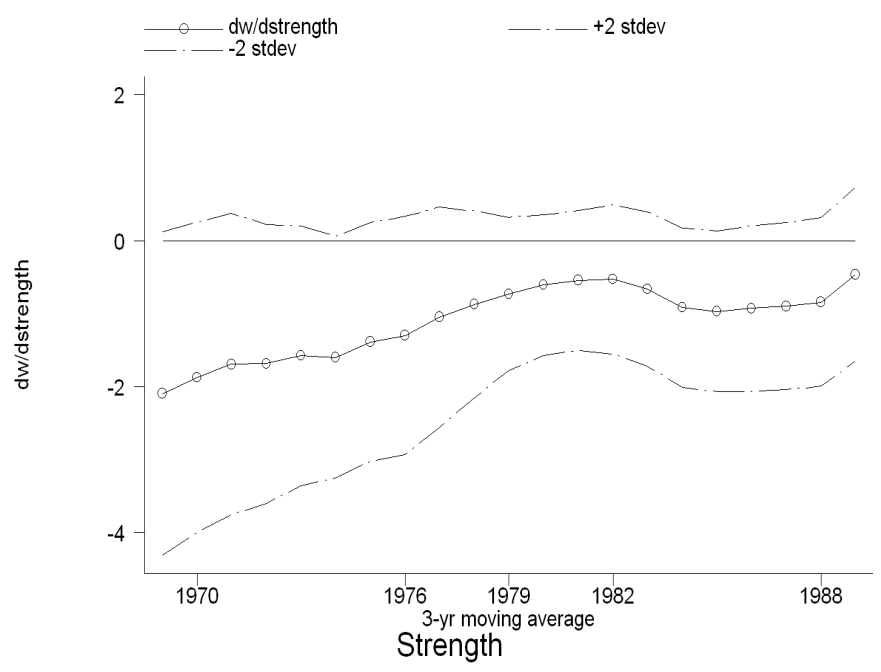

is less valuable. These cross effects, together with small direct effects of strength and people skills on wages, end up making occupations that require higher people skills or more strength to be not significantly associated with higher wages. This is shown in Figures 5 and 6 and in Table 4. Similar effects are observed when the values of strength and people skills are measured by education groups. Once cognitive and motor skills have been controlled for, changes in strength and people skill requirements do not affect wages significantly, except that people skills are becoming less valuable to college graduates.

\section{Skill Prices and Residual Inequality}

Could the estimated change in skill prices account for the observed rise in residual inequality? Table 6 shows the cognitive to motor intensity by percentile of the wage distribution for each education group. Throughout the period, within high school and college graduates, the top of the wage distribution is comprised of occupations relatively intensive in cognitive skills. On the other side, concentrated at the bottom of the wage distribution are occupations intensive in motor skills. As a consequence, the observed rise in price of cognitive skills and the decrease in price of motor skills should be expected to have raised 
Figure 6: Price of People Skills.

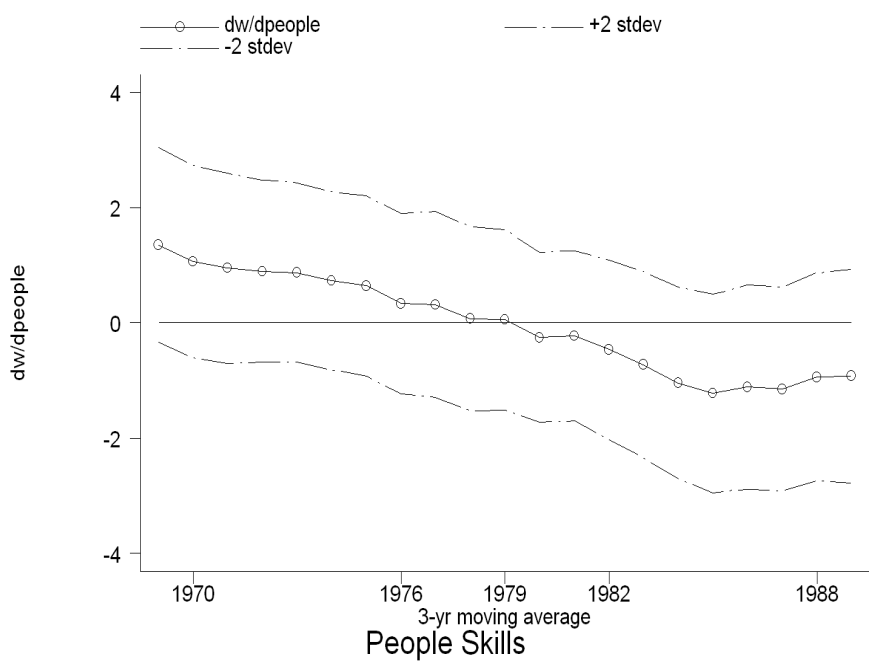

within education group inequality.

To further illustrate this point, Figures 7 and 8 show the static effects on the wage distribution of college and high school graduates of a $100 \%$ increase in the price of cognitive skills and a $50 \%$ decrease in the price of motor skills. ${ }^{22}$ At a given year, these figures show the effects of these hypothetical changes on the wage distribution. Each figure shows two wage densities, one with actual skill prices and the other with the hypothetically changed skill prices. ${ }^{23}$

Over time, however, skill prices change together with skill distributions and with changes in unobserved characteristics. The question then becomes how much of the observed changes in residual inequality can be accounted for by changes in skill prices versus changes in the distribution of skills versus changes in unobservables.

The first column in Table 7 shows the actual change in the ratio of the 90th to the 10th percentile of the wage distribution and summarizes the patterns of residual inequality for different education groups over the period. The first take-away message is that the residual

\footnotetext{
${ }^{22}$ Such a change in the prices of cognitive and motor skills is roughly what our previous estimates suggest actually happened in the US economy between the early 1970s and the early 1990s.

${ }^{23}$ Results shown are for the year 1980, but the same patterns arise irrespectively of the year in which the "experiment" is conducted.
} 
Figure 7: Wage density change when the price of cognitive skills doubles and that of motor skills is cut in half - high school graduates.

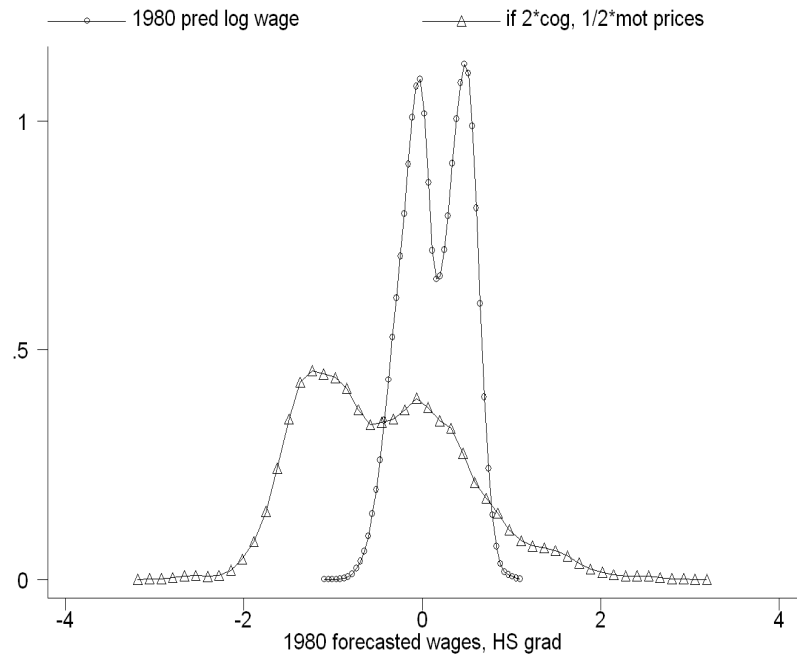

Figure 8: Wage density change when the price of cognitive skills double and that of motor skills is cut in half - college graduates.

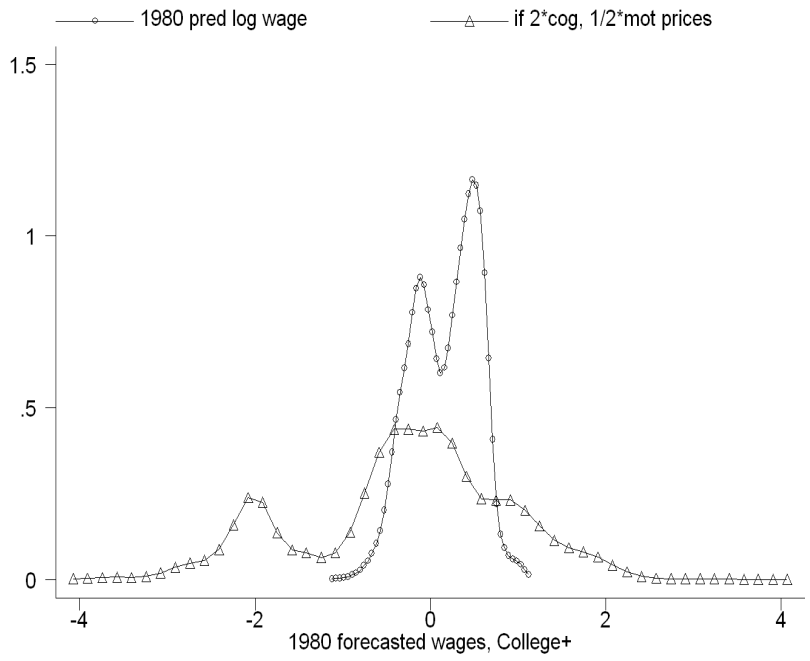


inequality changed very differently for different education groups and for different time periods. In the 1975-1980 period, for example, inequality did not rise within any education group. Wage inequality among workers with less than a high school degree increased by only $7.7 \%$ over the 1969-1989 period, less than a third of the increase within high school $(22.3 \%)$ and college $(25.9 \%)$ graduates.

We then use the full distributional accounting framework, outlined in detail in Juhn et al. (1993), to obtain a formal decomposition of the change in inequality over time into the following components: observed quantities, observed prices, and unobserved factors. Changes due to observed quantities include changes in the age and experience structures of the labor force and in occupational composition, that is, changes in all the variables included in the $\mathbf{X}$ and $\mathbf{Z}$ vectors. Observed price changes measure the effects of changes in the prices of the above quantities. Note that since we focus on within education group changes, changes in the education premium or in the education composition of the labor force do not play any role in the analysis.

Letting $\theta$ be the percentile in the residual distribution of equation 4 and letting anything denoted by a bar be the average of that parameter or set of variables over time, we can re-write equation 4 as follows: ${ }^{24}$

$$
\begin{aligned}
\log w_{i t} & =\left\{X_{i t} \bar{\beta}+Z_{i t} \bar{\gamma}\right\}+\left\{X_{i t}\left(\beta_{t}-\bar{\beta}\right)+Z_{i t}\left(\gamma_{t}-\bar{\gamma}\right)\right\}+ \\
& +\left\{\overline{F^{-1}}\left(\theta_{i t} \mid X, Z\right)+\left(F^{-1}\left(\theta_{i t} \mid X, Z\right)-\overline{F^{-1}}\left(\theta_{i t} \mid X, Z\right)\right)\right\}
\end{aligned}
$$

where $F$ is the cumulative distribution of the residuals in equation 4 . The terms inside the first brackets capture the effects of the observed quantity changes in the wage distribution. The terms inside the second brackets capture the effects of observed price changes, and the terms inside the third brackets capture the effect of unobserved factors.

Columns $2-5$ in Table 7 show the contribution of each of these components to the changes in within group inequality. As previously stated, in the 1975-1980 period, inequality did not

\footnotetext{
${ }^{24}$ For a detailed description see Juhn, Murphy, and Pierce (1993).
} 
rise within any education group nor for the overall sample. For workers with less than a high school degree, within group inequality increased in the 1980s only and by 10\%. About 35\% of such a rise is explained by changes in observables quantities. For high school graduates, inequality increased by $8.5 \%$ between 1969 and 1975 and by $12.4 \%$ in the $1980 \mathrm{~s}$. In the first of those periods, almost $50 \%$ of the changes is explained by changes in observable quantities and prices while in the second one only $20 \%$ can be accounted by observables.

College graduates are the ones for whom inequality increased the most. In the 19691975 period alone, the ratio of the 90 th to the 10 th percentile increased by $17.9 \%$. Of these changes, about $40 \%$ were due to changes in prices of observable skills, another $45 \%$ by work force and occupational composition changes, and only $15 \%$ were due to unobservable factors. In the 1980s, inequality within college graduates increased by $6 \%$, all of it accounted for by unobservable factors.

\section{Skill Prices and the Male-Female Wage Gap}

Could changes in skill prices also be behind the narrowing of the male-female wage gap? ${ }^{25}$ A logic similar to that applied in the previous section can be used here. If females are in occupations intensive in cognitive skills relative to motor skills when compared to males, or if they move into occupations intensive in cognitive skills at a faster rate than men, the observed changes in skill prices can explain why female wages have been catching up with male wages. Moreover, it can do so without relying on gender-specific factors.

It is well established in the literature that females are, on average, less skilled than males. That is certainly true in our data and in the skill measures developed in this paper, as can be seen in Table 8. However, Table 8 also shows that throughout the period women were moving into cognitive-intensive occupations while men were moving out of these occupations. For college graduates, for example, the ratio of cognitive to motor skills in occupations held by women went from 1.07 in 1970 to 1.14 in 1990 . For men, the equivalent numbers went

\footnotetext{
${ }^{25}$ For a detailed discussion on the patterns of changes in the male-female wage gap and their possible drivers, see Blau and Kahn (1997) and Altonji and Blank (1999).
} 
from 1.14 in 1970 to 1.13 in 1990 . For high school graduates, the change is even stronger. Females went from being in occupations requiring a ratio of cognitive to motor skills of 0.98 in 1970 to 1.06 in 1990, while men went from being in occupations requiring a ratio of 1.00 in 1970 to 1.01 in 1990. This compositional change, together with the estimated changes in skill prices, certainly contributed to the narrowing of the male-female wage gap. ${ }^{26}$

In order to distinguish how much of the narrowing in the male-female wage gap is due to occupation and skill composition changes and how much is due to changes in skills prices, we use the Juhn, Murphy, and Pierce (1993) decomposition. Given our interest in whether changes in skill prices can account for the narrowing of the male-female gap without relying on gender-specific factors, we do not impose labor market segmentation for males and females; therefore, we estimate equation 4 jointly for men and women.

The first column in Table 9 shows the observed decrease in the male-female wage gap in the whole sample as well as within education groups. Confirming other findings in the literature, the male-female wage gap declined within each education group, and the bulk of such decline occurred in the 1980s. Columns 2 and 3 show that changes in prices, including skill prices, quantitatively explain virtually all the observed closing of the wage gap. As women moved into more cognitive-intensive occupations, the gender wage gap was narrowed as the relative returns to these skills dramatically increased.

Table 9 also shows that labor force compositional changes, which could be associated with changes in discrimination patterns, also contributed to the decline in the gender wage gap. As in Blau and Kahn (1997), we attribute this to improvements in the compositional mix (particularly in experience levels) of the employed, especially for high school graduate women. Among college graduate women, however, changes in observable quantities contributed significantly less to the narrowing in the male-female wage gap, particularly between the mid-1970s and mid-1980s when it actually contributed to increasing the gender gap. This may be explained by the lag in work experience accumulation of college-going

\footnotetext{
${ }^{26}$ While it would be interesting to speculate on why women and men were moving into various occupations, investigating the causes for these shifts in occupational distribution are beyond the scope of the current paper. We discuss some possible hypotheses in the Conclusions.
} 
cohorts of women as well as the increase in their overall supply.

\section{Discussion and Conclusions}

In this paper we estimate prices of 4 groups of workers' skills at their jobs: cognitive skills, motor skills, people skills, and physical demands. We find that the two major trends characterizing the U.S. labor market during the 1970s and 1980s - rising income inequality and the narrowing of the male-female wage gap - have a common source: the increase in price of cognitive skills and the decrease in price of motor skills.

Most previous studies on how skill prices affected the wage distribution tend to think of skills along a single dimension, such as ability or cognitive functioning. This is the approach taken by studies such as Grogger and Eide (1995) and Murnane, Willet, and Levy (1995). Our database allows us to examine changes in the returns to a multidimensional vector of labor market skills, even within education groups and across males and females.

We show that, in contrast to the prevailing view that there has been a general increase in the returns to all types of skills, throughout the 1968-1990 period the returns to cognitive skills increased while the returns to motor skills strongly declined. In addition, we show that these skill prices varied across education groups and, over time, changed differentially across education groups.

The skill price changes we estimate in the paper explain a large fraction of the observed rise in "residual inequality" and of the narrowing of the wage gap between males and females. Given that the top of the wage distribution within college and high school graduates are in occupations intensive in cognitive skills relative to motor skills, an increase in the relative price of the former widens the wage gap, even within these education groups. Indeed, we estimate that changes in skill prices explain up to $40 \%$ of the rise in inequality among college graduates.

Meanwhile previous studies on the male-female wage gap find increased inequality and rising returns to skills pushed for the widening of the gender-pay gap instead of the observed 
narrowing. ${ }^{27}$ By using our multidimensional measures of skills requirements of jobs, we find that, even though women have less of these skills, throughout the period they moved into occupations intensive in cognitive skills relative to motor skills. Men, meanwhile, did the opposite and, on average, were increasingly in occupations relatively more intensive in motor skills. In 1970, college graduate females were, on average, in occupations $7 \%$ less intensive in cognitive skills than college graduate men. By 1980, the situation was reversed and females were, on average, in occupations $1 \%$ more cognitive intensive. As a result, women were better positioned than men to take advantage of the rise in the relative price of cognitive skills throughout the 1980s. Such mechanism explains virtually all of the observed closing of the male-female wage gap without relying on gender-specific factors.

The existing literature suggests that rising inequality and the narrowing of the genderpay gap do not have a common cause. In this paper we show they do. An alternative unified explanation is proposed more recently by Mulligan and Rubinstein (2004). They argue that once women's self-selection in the decision to work is controlled for, there is no actual narrowing in the gender-pay gap. It is certainly true that changes in unobserved characteristics of women who participate in the labor force can account for the observed narrowing of the gender-pay gap. Potentially, this can be the driver behind the increase in price of cognitive skills that we estimate. On the other hand, one would also expect that changes in the self-selection patterns of women's decision to work also reflect changes in the occupations women choose to sort into. We examined the occupation composition of women and men using a finely defined occupation classification, and we do find that women were increasingly employed in more cognitive intensive jobs relative to men. However, our decomposition shows that the effects of changes in the occupation distribution of women explain very little of the narrowing of the wage gap. Therefore, self-selection issues might have played a role, but only by affecting the "quality" of women within narrowly defined

\footnotetext{
${ }^{27}$ This is not to say that previous studies have found all aggregate labor market changes to have disadvantaged women, only that rising skill prices have disadvantaged them. For instance, studies of industry-level shifts over time have shown that women have benefited relative to men with the decline of manufacturing (see studies in Altonji and Blank (1999) and Devereux (2005)).
} 
occupations. We would argue that such a margin could hardly account for the narrowing of the wage gap.

A valid question is also to what extent would our results change had we estimated a multi-sector Roy model instead of the hedonic price model we used. Quite clearly, in the Roy model the results we find would be even more pronounced. The Roy model predicts that, as a consequence of a price increase in cognitive skills, the quantity of cognitive skills held by the marginal entrants into "cognitive jobs" declines, and thus our estimated increase in cognitive prices would be even higher. ${ }^{28}$

Meanwhile, previous studies on the effects of skill prices on the wage distribution also tend to think of skills along a single dimension, such as ability or cognitive function. While other individual traits, such as strength, are certainly skills in some jobs, few studies have measured non-cognitive skill requirements and their labor market returns. One of these is a recent study by Ingram and Neumann (2005). Using the fourth Edition DOT and the CPS, they estimate the returns to various skills and find, as we do, that variation in job skills contributed to increased residual wage inequality. While these findings are similar, we obtain a unified explanation for the two major changes in the structure of the U.S. labor market over this period: rising inequality and the male-female wage gap. Our study also addresses two implicit assumptions in their analysis: there were no changes in skill requirements of jobs over this period and there are no skill complementarities in the U.S. labor market. ${ }^{29}$ Relaxing these assumptions turns out to be very important in both consistently estimating returns to skills and in explaining what happened over this period. Between 1970 and 1991, skill requirements were observed to have changed for almost 2500 occupations. In addition, some labor market skills are very complementary, such as motor skills and strength, while others are substitutes, such as cognitive skills and strength; in the 1980s cognitive and motor skills became more complementary.

\footnotetext{
${ }^{28}$ Estimating a Roy model with hundreds of occupations is also very cumbersome (see Dahl (2002)), and unfeasible given our lack of individual-level data on skill vectors.

${ }^{29}$ The latter assumption is implicit in their analysis by construction of orthogonal skill indices and in not allowing for skill interactions in the estimation.
} 
There is also a vast literature that has tried to explain increased income and wage inequality in terms of changes in the supply and demand for skills in the U.S. labor market, in labor market institutions (e.g., unions) and regulations (e.g., minimum wage) over this period. $^{30}$ What appears to be an emerging consensus from this body of work is that increased inequality is due more to an increased demand for more skilled workers, likely spawned by skill-biased technical change (SBTC) as opposed to international trade. While it is appealing to speculate on the sources of our estimated skill price changes (e.g., supply vs. demand factors), it is clearly beyond the scope of this paper. Current studies provide indirect evidence that changes in skill demand are likely to be more important in explaining the change in relative skill prices we estimate. More specifically, utilizing the same database we use in our paper, Autor, Levy, and Murnane (2003) provide evidence for SBTC by showing how computerization alters job skill demands. In addition, they estimate that task changes explain a large chunk of relative skill demands shifts. An extension of our paper would be to estimate the skill content of technological change, and allow for a test of SBTC versus international trade.

\footnotetext{
${ }^{30}$ See Katz and Autor (1999) for a survey of these explanations.
} 
Table 2:

Means of Skill Indices by Educational Group.

\begin{tabular}{|c|c|c|c|c|c|c|}
\hline & \multicolumn{6}{|c|}{ Cognitive Skills } \\
\hline & 1970 & 1976 & 1979 & 1982 & 1988 & 1990 \\
\hline Less than HS & 94 & 94 & 96 & 96 & 96 & 96 \\
\hline HS grad & 99 & 99 & 101 & 101 & 101 & 101 \\
\hline College \& more & 108 & 109 & 110 & 110 & 109 & 110 \\
\hline \multicolumn{7}{|l|}{ Test: HS=College } \\
\hline \multirow[t]{3}{*}{ T-statistic } & -89.8 & -110.0 & -110.0 & -120.0 & -120.0 & -130.0 \\
\hline & \multicolumn{6}{|c|}{ Motor Skills } \\
\hline & 1970 & 1976 & 1979 & 1982 & 1988 & 1990 \\
\hline Less than HS & 100 & 100 & 100 & 99 & 99 & 99 \\
\hline HS grad & 101 & 101 & 99 & 99 & 99 & 99 \\
\hline College \& more & 97 & 97 & 98 & 98 & 98 & 98 \\
\hline \multicolumn{7}{|l|}{ Test: HS=College } \\
\hline \multirow[t]{3}{*}{ T-statistic } & 27.7 & 34.9 & 14.9 & 13.0 & 10.0 & 10.5 \\
\hline & \multicolumn{6}{|c|}{$\overline{\text { Strength }}$} \\
\hline & 1970 & 1976 & 1979 & 1982 & 1988 & 1990 \\
\hline Less than HS & 106 & 106 & 103 & 103 & 103 & 103 \\
\hline HS grad & 100 & 100 & 98 & 98 & 98 & 98 \\
\hline College \& more & 96 & 96 & 94 & 94 & 94 & 94 \\
\hline \multicolumn{7}{|l|}{ Test: HS=College } \\
\hline \multirow[t]{3}{*}{ T-statistic } & 41.7 & 56.0 & 53.3 & 56.5 & 59.7 & 63.5 \\
\hline & \multicolumn{6}{|c|}{ People Skills } \\
\hline & 1970 & 1976 & 1979 & 1982 & 1988 & 1990 \\
\hline Less than HS & 96 & 96 & 97 & 97 & 97 & 98 \\
\hline HS grad & 99 & 99 & 100 & 100 & 101 & 101 \\
\hline College \& more & 109 & 110 & 109 & 109 & 109 & 109 \\
\hline Test: $\mathrm{HS}=$ College & & & & & & \\
\hline T-statistic & -71.1 & -83.9 & -87.5 & -93.1 & -94.2 & -97.7 \\
\hline
\end{tabular}

Note: All the t-statistics significant at $1 \%$. 
Table 3:

a) Pairwise Correlation Between Skill Requirements 1968-1977.

\begin{tabular}{l|cccc}
\hline & Cognitive & Motor & Strength & People \\
\cline { 2 - 5 } Cognitive & 1 & $\cdot$ & $\cdot$ & $\cdot$ \\
Motor & .06 & 1 & $\cdot$ & $\cdot$ \\
Strength & -.55 & .22 & 1 & $\cdot$ \\
People & .66 & -.30 & -.45 & 1 \\
\hline
\end{tabular}

Table 3 (cont.):

b) Pairwise Correlation Between Skill Requirements 1978-1991.

\begin{tabular}{l|cccc}
\hline & Cognitive & Motor & Strength & People \\
\cline { 2 - 5 } Cognitive & 1 & $\cdot$ & $\cdot$ & $\cdot$ \\
Motor & .23 & 1 & $\cdot$ & $\cdot$ \\
Strength & -.54 & .29 & 1 & $\cdot$ \\
People & .64 & -.14 & -.43 & 1 \\
\hline
\end{tabular}

Table 4:

Hedonic Prices of Skill $\left(\frac{\partial w}{\partial(\text { skill })}\right)$.

\begin{tabular}{lcccccc}
\hline Skill & \multicolumn{7}{c}{ Years } \\
& $68-70$ & $71-76$ & $77-79$ & $80-82$ & $83-88$ & $89-90$ \\
\cline { 2 - 7 } Cognitive Skills & 1.28 & 3.33 & 3.28 & 3.49 & 5.16 & 5.65 \\
& $(1.1)$ & $(1.0)$ & $(0.9)$ & $(0.7)$ & $(0.8)$ & $(0.9)$ \\
Motor Skills & 3.10 & 2.95 & 2.99 & 2.73 & 2.17 & 2.21 \\
& $(0.7)$ & $(0.7)$ & $(0.7)$ & $(0.6)$ & $(0.6)$ & $(0.6)$ \\
Strength & -2.03 & -1.52 & -0.84 & -0.48 & -0.88 & 0.21 \\
& $(1.1)$ & $(0.8)$ & $(0.6)$ & $(0.4)$ & $(0.5)$ & $(0.6)$ \\
People Skills & 1.36 & 0.77 & 0.05 & -0.31 & -1.17 & -0.85 \\
& $(0.8)$ & $(0.7)$ & $(0.7)$ & $(0.7)$ & $(0.8)$ & $(0.9)$ \\
\hline
\end{tabular}

Note: Values are average prices within the years indicated. Associated standard errors are in parentheses. Actual point estimates of parameters are reported in Table 17 in the Appendices. Point estimates of other controls are also reported in the Appendices. To derive hedonic prices, estimates are evaluated at the mean of other indices (100) and multiplied by average weekly wage levels in that year. 
Table 5:

Hedonic Prices of Skill by Educational Group $\left(\frac{\partial w}{\partial(s k i l l)}\right)$.

\begin{tabular}{lcccccc}
\hline Skill & \multicolumn{7}{c}{ Years } \\
& $68-70$ & $71-76$ & $77-79$ & $80-82$ & $83-88$ & $89-90$ \\
\cline { 2 - 7 } Cognitive Skills & & & & & & \\
Less than HS & 0.07 & 1.25 & 0.51 & 1.28 & 1.74 & 1.07 \\
& $(1.7)$ & $(1.4)$ & $(1.4)$ & $(1.2)$ & $(1.4)$ & $(1.4)$ \\
HS grad & 2.29 & 3.76 & 2.99 & 2.98 & 4.04 & 4.82 \\
& $(1.3)$ & $(1.2)$ & $(1.0)$ & $(0.8)$ & $(0.9)$ & $(1.0)$ \\
College+ & 6.42 & 9.91 & 9.17 & 8.93 & 12.16 & 14.10 \\
& $(1.0)$ & $(1.0)$ & $(1.1)$ & $(1.0)$ & $(1.1)$ & $(1.2)$ \\
\hline Motor Skills & & & & & & \\
Less than HS & 5.09 & 4.12 & 4.69 & 4.30 & 3.88 & 3.82 \\
& $(1.1))$ & $(1.1)$ & $(1.2)$ & $(1.0)$ & $(1.1)$ & $(1.1)$ \\
HS grad & 2.90 & 2.61 & 3.04 & 3.01 & 2.66 & 2.48 \\
& $(0.7)$ & $(0.7)$ & $(0.7)$ & $(0.6)$ & $(0.7)$ & $(0.7)$ \\
College+ & -3.50 & -0.74 & -0.89 & -0.65 & -1.07 & -0.74 \\
& $(1.3)$ & $(0.8)$ & $(0.8)$ & $(0.8)$ & $(0.9)$ & $(1.0)$ \\
\hline Strength & & & & & & \\
Less than HS & -2.97 & -2.01 & -1.16 & -0.58 & -1.51 & -1.41 \\
& $(1.8)$ & $(1.4)$ & $(1.0)$ & $(0.8)$ & $(0.9)$ & $(0.9)$ \\
HS grad & -2.24 & -1.26 & -0.93 & -0.57 & -1.07 & -0.64 \\
& $(1.1)$ & $(0.9)$ & $(0.7)$ & $(0.5)$ & $(0.6)$ & $(0.7)$ \\
College+ & -0.74 & -0.94 & -0.76 & -1.08 & -2.00 & -1.10 \\
& $(1.1)$ & $(0.9)$ & $(0.8)$ & $(0.7)$ & $(0.8)$ & $(0.9)$ \\
\hline People Skills & & & & & & \\
Less than HS & 1.03 & 0.85 & 0.33 & 0.00 & -0.44 & -0.04 \\
& $(0.9)$ & $(0.9)$ & $(1.1)$ & $(1.0)$ & $(1.2)$ & $(1.2)$ \\
HS grad & 0.45 & -0.15 & -0.43 & -0.62 & -1.42 & -1.14 \\
& $(0.8)$ & $(0.8)$ & $(0.9)$ & $(0.8)$ & $(1.0)$ & $(1.1)$ \\
College+ & 7.33 & 5.45 & 3.05 & 2.01 & 0.75 & 2.43 \\
& $(0.9)$ & $(1.3)$ & $(1.1)$ & $(1.0)$ & $(1.2)$ & $(1.5)$ \\
\hline & & & & & & \\
& & & & & & \\
& & &
\end{tabular}

Note: Values are average prices within the years indicated. Associated standard errors are in parentheses. Actual point estimates of regression coefficients are reported in Table 18 in the Appendices. Point estimates of other controls are also reported in the Appendices. To derive hedonic prices, estimates are evaluated at the mean of other indices(100) and multiplied by average weekly wage levels in that year. 
Table 6:

Cognitive to motor intensity by educational group and age percentile .

\begin{tabular}{|c|c|c|c|c|}
\hline \multirow{4}{*}{$\begin{array}{l}\mathbf{1 9 7 0} \\
\text { less than HS }\end{array}$} & \multicolumn{4}{|c|}{ Wage distribution percentile } \\
\hline & 10th & 25 th & 75th & 90th \\
\hline & 0.96 & 0.95 & 0.94 & 0.95 \\
\hline & $(0.07)$ & $(0.08)$ & $(0.09)$ & $(0.09)$ \\
\hline \multirow[t]{2}{*}{ HS grads } & 0.98 & 0.98 & 1.00 & 1.02 \\
\hline & $(0.09)$ & $(0.09)$ & $(0.12)$ & $(0.12)$ \\
\hline \multirow[t]{2}{*}{ College +} & 1.09 & 1.10 & 1.12 & 1.13 \\
\hline & $(0.15)$ & $(0.14)$ & $(0.11)$ & $(0.11)$ \\
\hline \multirow{3}{*}{$\begin{array}{l}\mathbf{1 9 8 0} \\
\text { less than HS }\end{array}$} & 10th & 25 th & 75 th & 90th \\
\hline & 0.99 & 0.98 & 0.97 & 0.97 \\
\hline & $(0.08)$ & $(0.08)$ & $(0.09)$ & $(0.09)$ \\
\hline \multirow[t]{2}{*}{ HS grad } & 1.02 & 1.02 & 1.04 & 1.05 \\
\hline & $(0.1)$ & $(0.1)$ & $(0.12)$ & $(0.12)$ \\
\hline \multirow[t]{2}{*}{ College+ } & 1.12 & 1.12 & 1.14 & 1.14 \\
\hline & $(0.14)$ & $(0.14)$ & $(0.12)$ & $(0.13)$ \\
\hline \multirow[t]{2}{*}{ Total } & 1.04 & 1.03 & 1.05 & 1.06 \\
\hline & $(0.12)$ & $(0.12)$ & $(0.13)$ & $(0.13)$ \\
\hline \multirow{3}{*}{$\begin{array}{l}\mathbf{1 9 9 0} \\
\text { less than HS }\end{array}$} & 10th & 25 th & 75 th & 90th \\
\hline & 0.99 & 0.98 & 0.98 & 0.98 \\
\hline & $(0.09)$ & $(0.08)$ & $(0.09)$ & $(0.1)$ \\
\hline \multirow[t]{2}{*}{ HS grad } & 1.03 & 1.03 & 1.05 & 1.06 \\
\hline & $(0.1)$ & $(0.11)$ & $(0.11)$ & $(0.11)$ \\
\hline \multirow[t]{2}{*}{ College+ } & 1.10 & 1.11 & 1.15 & 1.16 \\
\hline & $(0.13)$ & $(0.13)$ & $(0.12)$ & $(0.13)$ \\
\hline \multirow[t]{2}{*}{ Total } & 1.04 & 1.04 & 1.07 & 1.08 \\
\hline & $(0.12)$ & $(0.12)$ & $(0.12)$ & $(0.13)$ \\
\hline
\end{tabular}

Note: Two-tailed t-tests (not reported) show the means reported above are statistically different across wage percentiles at $1 \%$ level, except for the "less than high school" category. 
Table 7:

Observable and unobservable components of changes in the ratio of the 90th to 10th percentile of the wage distribution.

\begin{tabular}{lcccc}
\hline & $\begin{array}{c}\text { Total } \\
\text { Period }\end{array}$ & $\begin{array}{c}\text { Observed } \\
\text { Change } \\
\text { Quantities }\end{array}$ & $\begin{array}{c}\text { Observed } \\
\text { Prices }\end{array}$ & $\begin{array}{c}\text { Unobserved } \\
\text { Prices and } \\
\text { Quantities }\end{array}$ \\
\cline { 2 - 5 } $1969-1975$ & 0.044 & -0.012 & -0.008 & 0.064 \\
$1975-1980$ & -0.046 & -0.025 & -0.049 & 0.028 \\
$1980-1989$ & 0.101 & 0.035 & -0.009 & 0.075 \\
\hline & \multicolumn{5}{c}{ high school graduates } \\
\cline { 2 - 5 } $1969-1975$ & 0.085 & 0.023 & 0.017 & 0.044 \\
$1975-1980$ & 0.013 & -0.004 & -0.024 & 0.041 \\
$1980-1989$ & 0.124 & 0.037 & -0.013 & 0.100 \\
\hline & \multicolumn{5}{c}{ College graduates } \\
\cline { 2 - 5 } $1969-1975$ & 0.179 & 0.078 & 0.071 & 0.030 \\
$1975-1980$ & 0.007 & 0.004 & -0.027 & 0.030 \\
$1980-1989$ & 0.068 & -0.044 & 0.001 & 0.111 \\
\hline & \multicolumn{5}{c}{ All sample } \\
$1969-1975$ & 0.058 & 0.023 & -0.002 \\
$1975-1980$ & -0.017 & -0.003 & -0.046 \\
$1980-1989$ & 0.167 & 0.025 & 0.044 & 0.037 \\
\hline \hline
\end{tabular}

Table 8:

Cognitive and motor skills of males and females.

\begin{tabular}{|c|c|c|c|c|c|c|}
\hline & \multicolumn{3}{|c|}{ Males } & \multicolumn{3}{|c|}{ Females } \\
\hline & \multicolumn{6}{|c|}{ Less than high school } \\
\hline & Cognitive & Motor & Ratio & Cognitive & Motor & Ratio \\
\hline 1970 & 95 & 101 & 0.94 & 92 & 97 & 0.94 \\
\hline 1980 & 97 & 101 & 0.96 & 95 & 97 & 0.98 \\
\hline \multirow[t]{3}{*}{1990} & 97 & 101 & 0.96 & 96 & 97 & 0.99 \\
\hline & \multicolumn{6}{|c|}{ high school Graduates } \\
\hline & Cognitive & Motor & Ratio & Cognitive & Motor & Ratio \\
\hline 1970 & 100 & 101 & 1.00 & 98 & 101 & 0.98 \\
\hline 1980 & 101 & 101 & 1.01 & 101 & 98 & 1.04 \\
\hline \multirow[t]{3}{*}{1990} & 101 & 100 & 1.01 & 102 & 97 & 1.06 \\
\hline & \multicolumn{6}{|c|}{ College Graduates } \\
\hline & Cognitive & Motor & Ratio & Cognitive & Motor & Ratio \\
\hline 1970 & 110 & 97 & 1.14 & 104 & 97 & 1.07 \\
\hline 1980 & 110 & 99 & 1.13 & 109 & 96 & 1.14 \\
\hline 1990 & 110 & 99 & 1.13 & 109 & 96 & 1.14 \\
\hline
\end{tabular}


Table 9:

Observable and unobservable components of changes in the male-female wage gap.

\begin{tabular}{lcccc}
\hline & $\begin{array}{c}\text { Total } \\
\text { Change }\end{array}$ & $\begin{array}{c}\text { Observed } \\
\text { Quantities }\end{array}$ & $\begin{array}{c}\text { Observed } \\
\text { Prices }\end{array}$ & $\begin{array}{c}\text { Unobserved } \\
\text { Prices and } \\
\text { Quantities }\end{array}$ \\
\hline \multirow{4}{*}{ Less than high school } \\
\cline { 2 - 5 } $1969-1989$ & -0.165 & -0.005 & -0.159 & -0.001 \\
$1969-1975$ & -0.020 & -0.030 & 0.010 & 0.000 \\
$1975-1980$ & -0.057 & -0.010 & -0.045 & -0.002 \\
$1980-1989$ & -0.087 & 0.035 & -0.124 & 0.001 \\
\hline & \multicolumn{5}{c}{ high school graduates } \\
\cline { 2 - 5 } $1969-1989$ & -0.184 & -0.054 & -0.133 & 0.003 \\
$1969-1975$ & 0.003 & -0.017 & 0.018 & 0.001 \\
$1975-1980$ & -0.053 & -0.021 & -0.031 & -0.001 \\
$1980-1989$ & -0.133 & -0.016 & -0.120 & 0.003 \\
\hline & \multicolumn{5}{c}{ College graduates } \\
\cline { 2 - 5 } $1969-1989$ & -0.088 & -0.004 & -0.063 & -0.022 \\
$1969-1975$ & -0.020 & -0.070 & 0.060 & -0.010 \\
$1975-1980$ & 0.002 & 0.043 & -0.034 & -0.007 \\
$1980-1989$ & -0.070 & 0.023 & -0.089 & -0.005 \\
& \multicolumn{5}{c}{ All sample } \\
\hline \multirow{3}{*}{$1969-1989$} & -0.173 & -0.036 & -0.135 & -0.002 \\
$1969-1975$ & -0.004 & -0.021 & 0.018 & -0.001 \\
$1975-1980$ & -0.044 & -0.004 & -0.039 & -0.002 \\
$1980-1989$ & -0.125 & -0.012 & -0.114 & 0.000 \\
\hline \hline
\end{tabular}




\section{References}

- Altonji, Joseph and Rebecca Blank. "Race and Gender in the Labor Market," in Handbook of Labor Economics Vol 3C. Orley Ashenfelter and David Card, eds. NorthHolland Elsevier Science, 1999, 3143-3251.

- Autor, David H., Frank Levy, and Richard Murnane, "The Skill Content of Recent Technological Change: An Empirical Exploration," Quarterly Journal of Economics, 118 (4), Nov. 2003, 1279-1333.

- Autor, David H., Lawrence Katz, and Alan Krueger, "Computing Inequality: Have Computers Changed the Labor Market?" Quarterly Journal of Economics, 113, 1998, 1169-1214.

- Berman, Eli, John Bound, and Zvi Griliches, "Changes in the Demand for Skilled Labor within U.S. Manufacturing: Evidence from the Annual Survey of Manufacturers," Quarterly Journal of Economics, 109 (2), May 1994, 367-97.

- Blau, Francine and Lawrence Kahn. "Rising Wage Inequality and the U.S. Gender Gap," American Economic Review 84(2), May 1994, 23-28.

- Blau, Francine and Lawrence Kahn, "Swimming Upstream: Trends in the Gender Wage Differential in the 1980s," Journal of Labor Economics, 1997, 15(1) pt 1, 1997, $1-42$.

- Borjas, George and Valerie Ramey, "Foreign Competition, Market Power, and Wage Inequality," Quarterly Journal of Economics, 110 (4), 1995, 1075-1110.

- Bound, John and George Johnson, "Changes in the Structure of Wages in the 1980s: An Evaluation of Alternative Explanations," American Economic Review, 82(3), Jun 1992, 371-392.

- Card, David and John DiNardo, "Skill-Biased Technological Change and Rising Wage 
Inequality: Some Problems and Puzzles," Journal of Labor Economics, 20, 2002, 733783.

- Current Population Survey, March 1968-1990, CPS Utilities, Santa Monica, CA: Unicon Research Corporation [producer and distributor], 2001.

- Dahl, Gordon, "Mobility and the Return to Education: Testing a Roy Model with Multiple Markets," Econometrica, 70(6), 2002, 2367-2420.

- Devereux, Paul, "Industry Growth and Decline and Changes in the Gender and Education Wage Gaps During the 1980s," Forthcoming at Industrial and Labor Relations Review.

- Epple, Dennis, "Hedonic Prices and Implicit Markets: Estimating Demand and Supply Functions for Different Products," The Journal of Political Economy, 95(1), 1987, 5980.

- Feenstra, Robert C. and Gordon H. Hanson, "Productivity Measurement and the Impact of Trade and Technology on Wages: Estimates for the U.S., 1972-1990," Quarterly Journal of Economics, 1998.

- Feenstra, Robert C. and Gordon H. Hanson, "Globalization Outsourcing, and Wage Inequality," NBER Working Paper 5424, January 1996.

- Goldin, Claudia, "The Long Road to the Fast Track: Career and Family," NBER Working Paper 10331, March 2004.

- Grogger, Jeff and Eric Eide, "Changes in College Skills and the Rise in the College Wage Premium," Journal of Human Resources, 30(2), 1995, 280-310.

- Heckman, James and Jose Scheinkman, "The Importance of Bundling in a GormanLancaster Model of Earnings," Review of Economic Studies, 54(2), Apr 1987, 243-255. 
- Ingram, Beth and George Neumann, "The Returns to Skill," forthcoming Labour Economics, 2005.

- Juhn, Chinhui, Kevin Murphy, and Brooks Pierce. "Inequality and the Rise in Returns to Skill," Journal of Political Economy 101(3), 1993, 410-442.

- Kahn, Shulamit and Kevin Lang, "Efficient Estimation of Structural Hedonic Systems," International Economic Review, 29 (1), Feb. 1988, 157-66.

- Katz, Lawrence and David Autor, "Changes in the Wage Structure and Earnings Inequality," in Handbook of Labor Economics Vol 3A. Orley Ashenfelter and David Card, eds. North-Holland Elsevier Science, 1999, 1463-1558.

- Katz, Lawrence and Kevin Murphy, "Changes in Relative Wages, 1963-1987: Supply and Demand Factors," Quarterly Journal of Economics, 107(1), 1992, 35-78.

- Leamer, Edward E., "In Search of the Stolper-Samuelson Effects On U.S. Wages," in Susan Collins eds., Exports, Imports, and the American Worker, Washington, D.C., The Brookings Institution, 1998.

- Levy, Frank and Richard Murnane, "U.S. Earnings Levels and Earnings Inequality: A Review of Recent Trends and Proposed Explanations," Journal of Economic Literature, XXX , Sept. 1992, 1333-1381.

- Mandelbrot, B., "Paretian Distributions and Income Maximization," Quarterly Journal of Economics, 1962, 76, 57-85.

- Miller, Anne Donald Treiman, Pamela Cain, and Patricia Roose, eds., Work, Jobs and Occupations: A Critical Review of the Dictionary of Occupational Titles, Washington, DC: National Academy Press, 1980.

- Mulligan, Casey and Yona Rubinstein, "The Closing of the Gender Gap as a Roy Model Illusion," NBER Working Paper 10892, November 2004. 
- Murnane, Richard, John B. Willett, and Frank Levy, "The Growing Importance of Cognitive Skills in Wage Determination", The Review of Economics and Statistics, $77(2), 1995,251-66$.

- National Academy of Science, Committee on Occupational Classification and Analysis. Dictionary of Occupational Titles (DOT): Part II-Fourth Edition Dictionary of DOT Scores for 1970 Census Categories [Computer file]. ICPSR 7845. Washington, DC: U.S. Dept of Commerce, Bureau of the Census [producer], 197?. Ann Arbor, MI: Inter-university Consortium for Political and Social Research [distributor], 2001.

- Rosen, Sherwin, "Hedonic Prices and Implicit Markets: Product Differentiation in Pure Competition," The Journal of Political Economy, 82 (1), Jan.-Feb. 1974, 34-55.

- Roy, A.D., "Some Thoughts on the Distribution of Earnings," Oxford Economic Papers 3, 1951, 135-46.

- Ruggles, Steven, Matthew Sobek et. al. Integrated Public Use Microdata Series: Version 3.0 [Machine-readable database]. Minneapolis, MN: Minnesota Population Center [producer and distributor], 2004.

- Rumberger, Russell W, "The Changing Skill Requirements of Jobs in the U.S. Economy," Industrial and Labor Relations Review, 34, 1981, 578-590.

- Sattinger, Michael, "Capital and the Distribution of Labor Earnings," Amsterdam, North-Holland, 1980.

- Tinbergen, Jan, "Some Results on the Distribution of Labour Incomes," International Economics Papers, 1951, 1, 195-207.

- Tinbergen, Jan, "On the Theory of Income Distribution," Weltwirtschaftliches Archiv, 1956, 77, 155-173, and in Selected Papers, Amsterdam, 1959, 243-63.

- U.S. Dept. of Labor, U.S. Employment Service, and the North Carolina Occupational Analysis Field Center. Dictionary of Occupational Titles (DOT): Revised Fourth Edi- 
tion, 1991 [Computer File]. Washington, DC: U.S. Dept. of Labor, U.S. Employment Service, and Raleigh, NC: North Carolina Occupational Analysis Field Center [producers], 1991. Ann Arbor, MI: Inter-university Consortium for Political and Social Research [distributor], 1994.

- Welch, Finis, "In Defense of Inequality," American Economic Review 89(2), May 1999, $1-17$.

- Wolff, Edward E., "Technology and the Demand for Skills," in Lex Borghans and Andries de Grip (Eds.), The Over Educated Worker?, Edward Elgar Publishing Ltd, 2000.

- Wolff, Edward E., "Skills and Changing Comparative Advantage," The Review of Economics and Statistics, 85 (1), Feb. 2003, 77-93. 


\section{A Robustness Checks}

\section{A.1 Alternative Ways of Constructing Skill Indices}

Since the DOT variables are highly related to each other, we first implement principal components or factor analysis on all 44 DOT Fourth Edition variables. In principal component analysis, the objective is to transform a given set of variables to a new set that will be pairwise uncorrelated. This is carried out by finding unit-length linear combinations of a given set of variables such that these variables' variance is maximized. The second subsequent factor is formed to maximize variance uncorrelated with the first factor, and so on.

Let $X$ be the $n \times 44$ matrix of DOT variables, where $n$ denotes the number of DOT occupations with 44 variables. The first factor is given by $z_{1}=X a_{1}$, where $a_{1}$ is a $k$-element vector. The objective is to choose $a_{1}$ to maximize $z_{1}^{\prime} z_{1}$ subject to $a_{1}^{\prime} a_{1}=1$. If the second factor is $z_{2}=X a_{2}$, we next wish to choose $a_{2}$ to maximize $z_{2}^{\prime} z_{2}$ subject to $a_{2}^{\prime} a_{2}=1$ and $a_{1}^{\prime} a_{2}=0$.

While generally not the case, factor analysis in our setting also enables us to identify the subset of DOT task measures that are particularly informative. We perform factor analysis over the more than 12,000 DOT occupations and obtain four interpretable factors that account for slightly more than $90 \%$ of total shared variance emerge from our analysis. Factor loadings from this analysis are reported in Appendix Table 11, with the definitions of DOT variables in Appendix Table $16 .^{31}$

The first factor, accounting for $45.82 \%$ of total shared variance, has eight variables with loadings of at least 0.7 (indicated in boldface). These include work complexity with data, GEDs, specific vocational preparation, and aptitudes for intelligence, verbal, and numeric. The high loadings of these variables suggests that the first factor is correlated with cognitive skill requirements for the job. A higher value of an index generated from

\footnotetext{
${ }^{31}$ Roos and Treiman (1980) perform a similar factor analysis and estimate scores of select DOT variables for 591 occupation codes in the 1970 census. These are the scores used in Wolff (2000, 2003). Our samples thus differ slightly in that the DOT sample has proportionately more occupations in the production sector than does the 1970 census. In practice, our stacked factor analyses obtain rather similar results as in Roos and Treiman (1980), which is also reassuring.
} 
this factor thus indicates substantive complexity is involved in carrying out the job. For instance, gedm measures mathematical development. At high gedm levels, workers are required to know advanced calculus and at low levels are required to only know how to perform arithmetic.

The second orthogonal factor, accounting for $26.73 \%$ of shared variance, show high loadings for items like motor coordination, finger and manual dexterity, and machine-related tasks (things). This factor reflects the motor skills required for the job. A higher value of an index from this factor would thus indicate high complexity of the job in relation to things, such as workers being required to set up and adjust machinery and to work it precisely. Finger dexterity also refers to the ability to manipulate objects with fingers rapidly and accurately.

The third orthogonal factor (accounting for $10.50 \%$ of shared variance) also reflects some aspects of physical job requirements, but the high loadings of variables such as streng (strength requirements), climb (job requires climbing and balancing), and hazard (presence of hazards on the job) suggest these are physical demands on the job. Lower values of an index generated from this factor thus indicate a relatively sedentary occupation. To contrast this with the second factor, the third factor indicates aspects of "brawn" requirements on the job as opposed to finer motor skills.

The fourth orthogonal factor, whose associated eigenvalue is still greater than 1, accounts for only $7.24 \%$ of total shared variance. This factor is correlated with leadership, management, and interpersonal skills, as shown by the high loadings of depl (dealing with people), people (job complexity in relation to people), and talk.

Our next step is to choose for each factor the set of items that loads strongly on the factor and only weakly on the others. The items included in each factor are indicated in boldface in Table 11 and are described in Table 16. The general rule of thumb we use is that items should load at least 0.5 on the primary factor and less than 0.3 on the remaining factors. Exceptions to this rule include considerations that the selected items will load fairly equally (e.g., we exclude repcon in the first factor because its loading is substantially less 
than the other items).

We then construct four skill indices from the four factor scores and merge these indices to the CPS to estimate our hedonic regression models. The results are similar to those reported in the text.

We also perform other sensitivity analyses with respect to the construction of the skill indices used in the paper. These include using factor loadings from a reduced factor analysis similar to the textual-based construction discussed in the text. That is, we construct four separate indices not necessarily orthogonal to each other. We experiment with different groupings of variables composing the four indices: cognitive, motor, physical, and people, as well as using means or aggregates (sums) of pre-determined grouped variables as the skill indices.

Across all these various skill constructs, the major increase in cognitive skill prices and decline in motor skills always hold. People skills and physical demands remain mildly significant to insignificant once other skills are controlled for.

Table 10: Factor Analyses for indices used in the text.

Panel (a) Cognitive Index 1968-1977.

\begin{tabular}{lccccc}
\hline \multirow{2}{*}{ Variables } & \multicolumn{4}{c}{ Factor Loadings } & $\begin{array}{c}\text { Scoring } \\
\text { Coefficients } \\
\text { for Index }\end{array}$ \\
\cline { 2 - 5 } & 1 & 2 & 3 & 4 & 0.09 \\
data & 0.87 & -0.01 & -0.10 & 0.09 & 0.28 \\
gedr & 0.95 & 0.02 & -0.05 & -0.08 & 0.15 \\
gedm & 0.90 & 0.20 & -0.01 & 0.02 & 0.14 \\
gedl & 0.92 & -0.07 & -0.09 & -0.07 & 0.16 \\
aptg & 0.92 & -0.11 & 0.14 & -0.03 & 0.16 \\
aptv & 0.90 & -0.22 & 0.03 & 0.06 & 0.09 \\
\hline Eigenvalue & 0.84 & 0.21 & 0.08 & 0.02 & \\
\% of Variance & 0.68 & 0.15 & 0.05 & 0.02 & \\
\hline
\end{tabular}


Table 11 (cont.): Factor Analyses for indices used in the text. Panel (b) Cognitive Index 1978-1991.

\begin{tabular}{lccccc}
\hline \multirow{2}{*}{ Variables } & \multicolumn{4}{c}{ Factor Loadings } & $\begin{array}{c}\text { Scoring } \\
\text { Coefficients } \\
\text { for Index }\end{array}$ \\
\cline { 2 - 5 } & 1 & 2 & 3 & 4 & 0.09 \\
data & 0.88 & 0.00 & -0.10 & 0.01 & 0.26 \\
gedr & 0.95 & -0.03 & -0.03 & -0.03 & 0.16 \\
gedl & 0.91 & 0.18 & 0.00 & 0.00 & 0.18 \\
aptg & 0.94 & -0.05 & -0.04 & -0.01 & 0.12 \\
aptv & 0.90 & -0.11 & 0.09 & -0.01 & 0.16 \\
aptn & 0.91 & -0.14 & 0.02 & 0.03 & 0.09 \\
\hline Eigenvalue & 0.85 & 0.16 & 0.06 & 0.01 & \\
\% of Variance & 5.75 & 0.09 & 0.02 & 0.00 & \\
\hline
\end{tabular}

Table 11 (cont.): Factor Analyses for indices used in the text.

\begin{tabular}{lccccc}
\multicolumn{5}{c}{ Panel (c) Motor Index 1968-1977. } \\
\cline { 2 - 5 } Variables & \multicolumn{5}{c}{$\begin{array}{c}\text { Scoring } \\
\text { Coefficients } \\
\text { for Index }\end{array}$} \\
\cline { 2 - 5 } things & 1 & 2 & 3 & 4 & 0.25 \\
aptf & 0.83 & 0.00 & -0.11 & -0.18 & 0.26 \\
aptk & 0.81 & -0.28 & -0.11 & 0.19 & 0.15 \\
aptm & 0.75 & -0.08 & -0.27 & 0.14 & 0.12 \\
apte & 0.69 & 0.18 & -0.17 & -0.03 & 0.05 \\
apts & 0.18 & 0.57 & -0.20 & -0.01 & 0.12 \\
aptp & 0.57 & 0.31 & 0.36 & -0.06 & 0.18 \\
aptc & 0.71 & -0.11 & 0.41 & 0.06 & 0.05 \\
sts & 0.44 & 0.21 & 0.11 & 0.19 & 0.09 \\
\hline Eigenvalue & 0.62 & -0.21 & -0.03 & -0.29 & \\
\% of Variance & 3.83 & 0.63 & 0.48 & 0.22 & \\
\hline
\end{tabular}


Table 11 (cont.): Factor Analyses for indices used in the text.

\begin{tabular}{|c|c|c|c|c|c|}
\hline \multirow[t]{2}{*}{ Variables } & \multicolumn{4}{|c|}{ Factor Loadings } & \multirow{2}{*}{$\begin{array}{c}\text { Scoring } \\
\text { Coefficients } \\
\text { for Index }\end{array}$} \\
\hline & 1 & 2 & 3 & 4 & \\
\hline things & 0.72 & 0.10 & 0.01 & 0.08 & 0.19 \\
\hline aptf & 0.72 & 0.09 & -0.23 & -0.05 & 0.20 \\
\hline aptk & 0.70 & 0.28 & -0.03 & 0.00 & 0.20 \\
\hline aptm & 0.67 & 0.30 & 0.04 & -0.03 & 0.18 \\
\hline apte & 0.25 & 0.14 & 0.34 & -0.01 & 0.05 \\
\hline apts & 0.67 & -0.33 & 0.14 & 0.09 & 0.18 \\
\hline aptp & 0.69 & -0.40 & -0.06 & 0.01 & 0.22 \\
\hline aptc & 0.40 & -0.19 & 0.03 & -0.15 & 0.07 \\
\hline sts & 0.01 & 0.05 & -0.10 & 0.14 & 0.00 \\
\hline Eigenvalue & 3.14 & 0.51 & 0.21 & 0.06 & \\
\hline$\%$ of Variance & 0.95 & 0.16 & 0.06 & 0.02 & \\
\hline
\end{tabular}

\section{A.2 Measurement Errors in Skill Requirements}

While the source of variation in DOT skill requirements we exploit are across jobs at a given point in time, our interpretation of changes over time in the prices of such skills may depend on whether the skill quantities being demanded are also changing over time. In particular, our estimates of skill prices $\gamma_{t}$ may be biased upward if skill quantities are measured with error and actual skills demanded have increased over time. As we mentioned in our discussion of the data, a revised fourth edition of DOT was released in 1991. Between 1977 and 1991, analysts reviewed, updated, and/or added 2,452 occupational definitions to the Dictionary.

As a robustness check, we re-estimate the hedonic models with skill indices generated excluding DOT occupations that were updated between 1977 and 1991. As reported in tables 12 and 13, all of our results are highly robust, both qualitatively and for almost all parameters quantitatively as well. 
Table 11: Factor Analyses on All DOT variables.

\begin{tabular}{lcccccc}
\hline & \multicolumn{7}{c}{ Rotated Factor Loadings } \\
\hline Variable & 1 & 2 & 3 & 4 & 5 & 6 \\
\hline data & $\mathbf{0 . 8 8}$ & 0.02 & -0.07 & 0.18 & -0.03 & -0.12 \\
gedr & $\mathbf{0 . 9 4}$ & 0.07 & -0.09 & 0.13 & -0.05 & 0.09 \\
gedm & $\mathbf{0 . 8 9}$ & 0.04 & -0.11 & -0.02 & 0.12 & -0.03 \\
gedl & $\mathbf{0 . 8 8}$ & -0.01 & -0.14 & 0.21 & -0.10 & 0.01 \\
aptg & $\mathbf{0 . 8 8}$ & 0.03 & -0.15 & 0.15 & -0.09 & 0.09 \\
aptv & $\mathbf{0 . 8 5}$ & -0.04 & -0.18 & 0.26 & -0.10 & -0.05 \\
aptn & $\mathbf{0 . 8 4}$ & 0.07 & -0.17 & -0.02 & 0.14 & 0.02 \\
svp & $\mathbf{0 . 9 0}$ & 0.10 & 0.11 & 0.06 & -0.01 & -0.04 \\
things & 0.14 & $\mathbf{0 . 7 7}$ & 0.14 & -0.28 & 0.10 & 0.04 \\
aptf & 0.13 & $\mathbf{0 . 8 3}$ & -0.11 & -0.08 & -0.05 & -0.08 \\
aptk & 0.01 & $\mathbf{0 . 8 1}$ & 0.00 & -0.04 & -0.03 & 0.12 \\
aptm & -0.16 & $\mathbf{0 . 6 5}$ & 0.30 & -0.28 & -0.05 & -0.14 \\
see & 0.10 & $\mathbf{0 . 6 4}$ & 0.03 & -0.22 & 0.13 & 0.21 \\
streng & -0.43 & 0.02 & $\mathbf{0 . 6 5}$ & -0.22 & -0.01 & -0.13 \\
apte & -0.16 & 0.13 & $\mathbf{0 . 6 1}$ & -0.08 & -0.08 & 0.27 \\
climb & -0.09 & 0.02 & $\mathbf{0 . 6 7}$ & -0.20 & 0.07 & -0.10 \\
stoop & -0.25 & 0.03 & $\mathbf{0 . 6 9}$ & -0.23 & 0.03 & -0.14 \\
hazard & -0.17 & 0.18 & $\mathbf{0 . 5 5}$ & -0.18 & 0.07 & 0.11 \\
out & -0.06 & 0.02 & $\mathbf{0 . 6 0}$ & -0.09 & 0.04 & 0.25 \\
people & 0.50 & -0.21 & -0.06 & $\mathbf{0 . 5 2}$ & -0.14 & 0.06 \\
depl & 0.20 & -0.18 & -0.14 & $\mathbf{0 . 9 4}$ & -0.01 & -0.02 \\
talk & 0.37 & -0.15 & -0.10 & $\mathbf{0 . 7 0}$ & 0.01 & 0.04 \\
aptq & 0.54 & 0.09 & -0.48 & 0.12 & 0.20 & -0.03 \\
apts & 0.46 & 0.36 & 0.33 & -0.24 & -0.11 & 0.09 \\
aptp & 0.45 & 0.61 & -0.01 & -0.13 & -0.12 & -0.11 \\
aptc & -0.11 & -0.40 & -0.14 & 0.07 & 0.30 & -0.01 \\
dcp & 0.58 & -0.37 & -0.07 & 0.23 & 0.03 & 0.06 \\
fif & 0.13 & 0.09 & -0.02 & 0.05 & -0.43 & 0.03 \\
influ & 0.23 & -0.25 & -0.06 & 0.30 & -0.35 & -0.11 \\
sjc & 0.46 & -0.03 & -0.02 & 0.24 & -0.36 & -0.08 \\
mvc & 0.48 & 0.12 & 0.19 & -0.23 & 0.26 & -0.07 \\
repcon & -0.69 & -0.17 & -0.06 & -0.20 & -0.12 & 0.27 \\
pus & -0.07 & 0.08 & 0.11 & 0.23 & 0.09 & 0.31 \\
sts & 0.15 & 0.56 & -0.05 & -0.44 & 0.34 & -0.07 \\
varch & 0.36 & 0.20 & 0.21 & 0.11 & 0.22 & -0.19 \\
reach & -0.47 & 0.57 & 0.16 & -0.26 & 0.06 & -0.07 \\
\hline \%var explain & 0.46 & 0.27 & 0.11 & 0.07 & 0.04 & 0.02 \\
Eigenvalue & 10.91 & 6.37 & 2.50 & 1.72 & 0.88 & 0.59 \\
\hline & & & & & &
\end{tabular}


Table 12: Hedonic Prices of Skill $\left(\frac{\partial w}{\partial(s k i l l)}\right)$ : Workers With No Change in Occupation Skill
Requirements.

\begin{tabular}{lcccccc}
\hline Skill & \multicolumn{7}{c}{ Years } \\
& $68-70$ & $71-76$ & $77-79$ & $80-82$ & $83-88$ & $89-90$ \\
\cline { 2 - 7 } Cognitive Skills & 1.70 & 3.38 & 3.26 & 3.03 & 4.20 & 5.37 \\
& $((1.1)$ & $(.95)$ & $(.86)$ & $(.73)$ & $(.84)$ & $(.94)$ \\
Motor Skills & 2.84 & 2.42 & 2.38 & 2.17 & 1.82 & 1.52 \\
& $(.63)$ & $(.63)$ & $(.6)$ & $(.54)$ & $(.59)$ & $(.64)$ \\
Strength & -1.94 & -0.89 & -0.70 & -0.80 & 1.03 & -0.75 \\
& $(1.05)$ & $(.85)$ & $(.73)$ & $(.61)$ & $(.71)$ & $(.76)$ \\
People Skills & 1.00 & 1.08 & 0.72 & 0.76 & 0.54 & 0.25 \\
& $(.6)$ & $(.59)$ & $(.56)$ & $(.54)$ & $(.66)$ & $(.79)$ \\
\hline
\end{tabular}

Note: Values are average prices within the years indicated. Associated standard errors are in parentheses. The hedonic prices are evaluated at the mean of other indices(100) and multiplied by average weekly wage level in that year. 
Table 13:

Hedonic Prices of Skill by Education Group $\left(\frac{\partial w}{\partial(s k i l l)}\right)$ : Workers With No Change in Occupation Skill Requirements

\begin{tabular}{lcccccc}
\hline Skill & \multicolumn{7}{c}{ Years } \\
& $68-70$ & $71-76$ & $77-79$ & $80-82$ & $83-88$ & $89-90$ \\
\cline { 2 - 7 } Cognitive Skills & \multicolumn{7}{c}{ coss than HS } & -0.58 & 0.94 & -0.08 & 0.12 & 1.08 & 0.90 \\
& $(1.62)$ & $(1.33)$ & $(1.24)$ & $(1.18)$ & $(1.39)$ & $(1.46)$ \\
HS grad & 1.95 & 3.05 & 2.59 & 2.28 & 3.08 & 4.28 \\
& $(1.11)$ & $(1.06)$ & $(1.02)$ & $(.8)$ & $(.93)$ & $(1.09)$ \\
College+ & 6.68 & 8.23 & 7.24 & 6.62 & 8.63 & 11.10 \\
& $(.72)$ & $(.9)$ & $(.82)$ & $(.79)$ & $(.91)$ & $(.96)$ \\
\hline Motor Skills & & & & & & \\
Less than HS & 4.34 & 3.37 & 3.63 & 3.03 & 2.43 & 2.11 \\
& $(1.06)$ & $(1.05)$ & $(.97)$ & $(.86)$ & $(.97)$ & $(1.03)$ \\
HS grad & 2.45 & 2.18 & 2.21 & 2.10 & 1.89 & 1.58 \\
& $(.58)$ & $(.62)$ & $(.63)$ & $(.57)$ & $(.63)$ & $(.69)$ \\
College+ & -1.84 & -1.07 & -0.78 & -0.21 & -0.90 & -1.38 \\
& $(.75)$ & $(.74)$ & $(.62)$ & $(.61)$ & $(.71)$ & $(.81)$ \\
\hline Strength & & & & & & \\
Less than HS & -2.95 & -1.63 & -1.49 & -1.68 & -1.31 & -1.38 \\
& $(1.95)$ & $(1.61)$ & $(1.35)$ & $(1.28)$ & $(1.4)$ & $(1.38)$ \\
HS grad & -2.02 & -0.92 & -0.82 & -0.75 & -0.93 & -0.81 \\
& $(1.06)$ & $(.91)$ & $(.88)$ & $(.68)$ & $(.82)$ & $(.93)$ \\
College+ & -1.92 & -0.22 & -0.28 & -0.83 & -0.97 & -0.36 \\
& $(.8)$ & $(.9)$ & $(.73)$ & $(.69)$ & $(.82)$ & $(.9)$ \\
\hline People Skills & & & & & & \\
Less than HS & 1.31 & 1.33 & 1.31 & 1.54 & 0.93 & 0.97 \\
& $(.71)$ & $(.76)$ & $(.77)$ & $(.78)$ & $(1.05)$ & $(1.02)$ \\
HS grad & 0.80 & 0.80 & 0.53 & 0.54 & 0.37 & 0.10 \\
& $(.59)$ & $(.62)$ & $(.61)$ & $(.57)$ & $(.71)$ & $(.88)$ \\
College+ & 4.25 & 4.88 & 3.03 & 2.81 & 2.55 & 2.63 \\
& $(.85)$ & $(.84)$ & $(.7)$ & $(.74)$ & $(.79)$ & $(1.07)$ \\
\hline
\end{tabular}

Note: Values are average prices within the years indicated. Associated standard errors are in parentheses. To derive hedonic prices, coefficient estimates are evaluated at the mean of other indices (100) and multiplied by average weekly wage levels in that year. 
Table 14:

The Skill Elasticity of Wages $\left(\frac{\partial \ln (w)}{\partial \ln (\operatorname{skill})}\right)$.

\begin{tabular}{lcccccc}
\hline Skill & \multicolumn{6}{c}{ Years } \\
& $68-70$ & $71-76$ & $77-79$ & $80-82$ & $83-88$ & $89-90$ \\
\cline { 2 - 7 } Cognitive Skills & 0.301 & 0.852 & 0.916 & 1.044 & 1.448 & 1.629 \\
& $(0.32)$ & $(0.27)$ & $(0.25)$ & $(0.23)$ & $(0.24)$ & $(0.26)$ \\
Motor Skills & 0.857 & 0.801 & 0.837 & 0.821 & 0.596 & 0.558 \\
& $(0.2)$ & $(0.19)$ & $(0.2)$ & $(0.19)$ & $(0.19)$ & $(0.19)$ \\
Strength & -0.542 & -0.395 & -0.236 & -0.164 & -0.248 & -0.129 \\
& $(0.29)$ & $(0.23)$ & $(0.17)$ & $(0.14)$ & $(0.15)$ & $(0.16)$ \\
People Skills & 0.308 & 0.141 & -0.043 & -0.133 & -0.385 & -0.305 \\
& $(0.22)$ & $(0.2)$ & $(0.22)$ & $(0.23)$ & $(0.25)$ & $(0.27)$ \\
\hline
\end{tabular}

Note: Values are average prices within the years indicated. Associated standard errors are in parentheses. Actual point estimates of parameters are reported in Table 17 in the appencices.

\section{A.3 The skill elasticity of wages}

The log-linear functional form in the text of the paper is such that the estimated skill prices have to be evaluated at the average real wage in the economy. Therefore, it is possible that part of the observed change over time in skill prices are in fact due to changes in the economy's real wage. In this section we present the skill elasticity of wages, defined as $\frac{\partial \ln (w)}{\partial \ln (\operatorname{Cog})}$, which are unit free. The results confirm the increasing impact of cognitive skills on wages and the decreasing impact on motor skills on wages. Table 14 confirms the same patterns previously found in the analysis in the body of the text. ${ }^{32}$

\footnotetext{
${ }^{32}$ Tables 19 and 20 in appendix B show the complete set of parameters.
} 
Table 15:

The Skill Elasticity of Wages by Educational Group $\left(\frac{\partial \ln (w)}{\partial \ln (\operatorname{skill})}\right)$.

\begin{tabular}{lcccccc}
\hline Skill & \multicolumn{7}{c}{ Years } \\
& $68-70$ & $71-76$ & $77-79$ & $80-82$ & $83-88$ & $89-90$ \\
\cline { 2 - 7 } Cognitive Skills & & & & & & \\
Less than HS & 0.049 & 0.407 & 0.228 & 0.565 & 0.713 & 0.497 \\
& $(0.47)$ & $(0.36)$ & $(0.4)$ & $(0.37)$ & $(0.39)$ & $(0.39)$ \\
HS grad & 0.660 & 1.058 & 0.911 & 0.991 & 1.296 & 1.564 \\
& $(0.34)$ & $(0.31)$ & $(0.29)$ & $(0.25)$ & $(0.26)$ & $(0.29$ \\
College+ & 1.149 & 1.889 & 1.988 & 2.072 & 2.590 & 2.985 \\
& $(0.26)$ & $(0.27)$ & $(0.3)$ & $(0.3)$ & $(0.31)$ & $(0.33)$ \\
\hline Motor Skills & & & & & & \\
Less than HS & 1.752 & 1.403 & 1.629 & 1.624 & 1.506 & 1.531 \\
& $(0.3)$ & $(0.28)$ & $(0.32)$ & $(0.29)$ & $(0.31)$ & $(0.32)$ \\
HS grad & 0.811 & 0.736 & 0.903 & 0.973 & 0.830 & 0.725 \\
& $(0.19)$ & $(0.19)$ & $(0.2)$ & $(0.19)$ & $(0.2)$ & $(0.2)$ \\
College+ & -0.664 & -0.186 & -0.269 & -0.250 & -0.292 & -0.257 \\
& $(0.32)$ & $(0.24)$ & $(0.25)$ & $(0.27)$ & $(0.26)$ & $(0.29$ \\
\hline Strength & & & & & & \\
Less than HS & -1.009 & -0.664 & -0.397 & -0.233 & -0.582 & -0.557 \\
& $(0.51)$ & $(0.38)$ & $(0.29)$ & $(0.25)$ & $(0.26)$ & $(0.26)$ \\
HS grad & -0.593 & -0.331 & -0.259 & -0.185 & -0.332 & -0.193 \\
& $(0.28)$ & $(0.24)$ & $(0.19)$ & $(0.15)$ & $(0.16)$ & $(0.18)$ \\
College+ & -0.046 & -0.120 & -0.143 & -0.215 & -0.350 & -0.139 \\
& $(0.29)$ & $(0.23)$ & $(0.21)$ & $(0.21)$ & $(0.22)$ & $(0.26)$ \\
\hline People Skills & & & & & & \\
Less than HS & 0.384 & 0.306 & 0.141 & 0.036 & -0.128 & 0.023 \\
& $(0.24)$ & $(0.23)$ & $(0.3)$ & $(0.31)$ & $(0.34)$ & $(0.35)$ \\
HS grad & 0.100 & -0.054 & -0.146 & -0.200 & -0.456 & -0.364 \\
& $(0.2)$ & $(0.21)$ & $(0.24)$ & $(0.25)$ & $(0.27)$ & $(0.3$ \\
College+ & 1.443 & 1.046 & 0.609 & 0.451 & 0.091 & 0.401 \\
& $(0.27)$ & $(0.38)$ & $(0.34)$ & $(0.34)$ & $(0.35)$ & $(0.43)$ \\
\hline
\end{tabular}

Note: Values are average prices within the years indicated. Associated standard errors are in parentheses. Actual point estimates of regression coefficients are reported in Table 18 in the appendices. 


\section{B Additional tables}


Table 16: Description of DOT Variables

\begin{tabular}{|c|c|}
\hline \multicolumn{2}{|c|}{ Variables comprising COGNITIVE SKILLS INDEX: } \\
\hline data & $\begin{array}{l}\text { complexity at which worker performs job in relation to data, from highest to lowest: } \\
\text { synthesizing, coordinating, analyzing, compiling, computing, copying, comparing }\end{array}$ \\
\hline gedr & $\begin{array}{l}\text { general educational development in reasoning required for job, ranging from being able to } \\
\text { apply logical or scientific thinking to wide range of intellectual and practical problems, to } \\
\text { being able to apply commonsense understanding to carry out simple instructions. }\end{array}$ \\
\hline gedm & $\begin{array}{l}\text { general educational development in mathematics required to perform job, from knowledge } \\
\text { of advanced calculus, modern algebra and statistics; algebra, geometry \& shop math; to } \\
\text { simple addition and subtraction. }\end{array}$ \\
\hline gedl & $\begin{array}{l}\text { general educational development in language required, from reading literature, writing } \\
\text { editorials \& speeches, and conversant in persuasive speaking \& debate; to reading at rate } \\
\text { of } 95-120 \text { words per minute or vocabulary of } 2,500 \text { words, and writing and speaking simple } \\
\text { sentences. }\end{array}$ \\
\hline aptg & $\begin{array}{l}\text { segment of the population possessing intelligence (or general learning ability) aptitude } \\
\text { for the job: top } 10 \% \text { of popn; top } 1 / 3 \text { except top } 10 \% \text {; middle third; lowest third except } \\
\text { bottom } 10 \% \text {; lowest } 10 \% \text { of popn }\end{array}$ \\
\hline aptv & $\begin{array}{l}\text { segment of the population possessing verbal aptitude for the job: top } 10 \% \text { of popn; top } \\
1 / 3 \text { except top } 10 \% \text {; middle third; lowest third except bottom } 10 \% \text {; lowest } 10 \% \text { of popn }\end{array}$ \\
\hline aptn & $\begin{array}{l}\text { segment of the population possessing numerical aptitude for the job: top } 10 \% \text { of popn; } \\
\text { top } 1 / 3 \text { except top } 10 \% \text {; middle third; lowest third except bottom } 10 \% \text {; lowest } 10 \% \text { of } \\
\text { popn }\end{array}$ \\
\hline \multicolumn{2}{|c|}{ Variables comprising MOTOR SKILLS INDEX: } \\
\hline things & $\begin{array}{l}\text { Complexity at which worker performs job in relation to things, from highest to low- } \\
\text { est: setting up; precision working; operating-controlling; driving-operating; manipulating; } \\
\text { tending; feeding; handling }\end{array}$ \\
\hline aptf & $\begin{array}{l}\text { segment of the population possessing finger dexterity (ability to manipulate objects with } \\
\text { fingers rapidly \& accurately) aptitude for the job: top } 10 \% \text { of popn; top } 1 / 3 \text { except top } \\
10 \% \text {; middle third; lowest third except bottom } 10 \% \text {; lowest } 10 \% \text { of popn }\end{array}$ \\
\hline Aptk & $\begin{array}{l}\text { segment of the population possessing motor coordination aptitude for the job: top } 10 \% \text { of } \\
\text { popn; top } 1 / 3 \text { except top } 10 \% \text {; middle third; lowest third except bottom } 10 \% \text {; lowest } 10 \% \\
\text { of popn }\end{array}$ \\
\hline aptm & $\begin{array}{l}\text { segment of the population possessing manual dexterity (ability to work with hands in } \\
\text { turning and placing motions) aptitude for the job: top } 10 \% \text { of popn; top } 1 / 3 \text { except top } \\
10 \% \text {; middle third; lowest third except bottom } 10 \% \text {; lowest } 10 \% \text { of popn }\end{array}$ \\
\hline apte & $\begin{array}{l}\text { segment of the population possessing eye-hand-foot coordination for the job: top } 10 \% \text { of } \\
\text { popn; top } 1 / 3 \text { except top } 10 \% \text {; middle third; lowest third except bottom } 10 \% \text {; lowest } 10 \% \\
\text { of popn }\end{array}$ \\
\hline apts & $\begin{array}{l}\text { segment of the population possessing spatial perception aptitude (ability to think visually } \\
\text { of geometric forms) for the job: top } 10 \% \text { of popn; top } 1 / 3 \text { except top } 10 \% \text {; middle third; } \\
\text { lowest third except bottom } 10 \% \text {; lowest } 10 \% \text { of popn }\end{array}$ \\
\hline aptp & $\begin{array}{l}\text { segment of the population possessing form perception (ability to perceive detail in objects) } \\
\text { aptitude for the job: top } 10 \% \text { of popn; top } 1 / 3 \text { except top } 10 \% \text {; middle third; lowest third } \\
\text { except bottom } 10 \% \text {; lowest } 10 \% \text { of popn }\end{array}$ \\
\hline Aptc & $\begin{array}{l}\text { segment of the population possessing color discrimination aptitude for the job: top } 10 \% \\
\text { of popn; top } 1 / 3 \text { except top } 10 \% \text {; middle third; lowest third except bottom } 10 \% \text {; lowest } \\
10 \% \text { of popn }\end{array}$ \\
\hline Sts & $\begin{array}{l}\text { Adaptability to situations requiring attainment of set limits, tolerances or } s \text { tandards (e.g., } \\
\text { operates a billing machine to transcribe from office records data; papers voter lists from of- } \\
\text { ficial registration; measures dimensions of bottle to verify setup of bottlemaking conforms } \\
\text { to standards }\end{array}$ \\
\hline
\end{tabular}


Table 16 (cont.): Description of DOT Variables

\begin{tabular}{|c|c|}
\hline \multicolumn{2}{|c|}{ Variable comprising STRENGH INDEX: } \\
\hline streng & $\begin{array}{l}\text { degree of strength requirements of job as measured by involvement in standing, walking, } \\
\text { sitting, lifting, carrying: from very heavy, heavy, medium, to light, sedentary. }\end{array}$ \\
\hline \multicolumn{2}{|c|}{ Variable comprising PEOPLE SKILLS INDEX: } \\
\hline people & $\begin{array}{l}\text { complexity at which worker performs job in relation to people, from highest to lowest: men- } \\
\text { toring; negotiating; instructing; supervising; diverting; persuading; speaking-signaling; } \\
\text { serving; taking instructions }\end{array}$ \\
\hline \multicolumn{2}{|c|}{ Variable not used in the analyzis: } \\
\hline aptq & $\begin{array}{l}\text { segment of the population possessing clerical perception (ability to proofread words \& } \\
\text { numbers, perceive detail in verbal or tabular material): top } 10 \% \text { of popn; top } 1 / 3 \text { except } \\
\text { top } 10 \% \text {; middle third; lowest third except bottom } 10 \% \text {; lowest } 10 \% \text { of popn }\end{array}$ \\
\hline depl & Adaptability to dealing with people beyond giving and receiving instructions \\
\hline Dcp & Adaptability to accepting responsibility for direction, control or $p$ lanning of an activity \\
\hline Fif & $\begin{array}{l}\text { Adaptability to situations involving interpretation of } f \text { eelings, } i \text { deas or } f \text { acts from personal } \\
\text { viewpoint }\end{array}$ \\
\hline Influ & $\begin{array}{l}\text { Adaptabilty to influencing people in their opinions, attitudes or judgments about ideas } \\
\text { or things }\end{array}$ \\
\hline Sjc & Adaptability to making evaluations or decisions based on sensory or judgmental criteria \\
\hline Mvc & Adaptability to making evaluations or decisions based on measurable or verifiable $c$ riteria \\
\hline repcon & Adaptability to performing repetitive work or to continuously performing the same work \\
\hline$\overline{P u s}$ & $\begin{array}{l}\text { Adaptability to performing under stress when confronted with emergency or dangerous } \\
\text { situations }\end{array}$ \\
\hline varch & $\begin{array}{l}\text { Adaptability to performing a variety of duties, often changing from one to another without } \\
\text { loss of efficiency }\end{array}$ \\
\hline climb & job requires climbing stairs, scaffolding, etc., \&/or balancing \\
\hline stoop & job requires stooping, kneeling, crouching, \&/or crawling \\
\hline Out & job involves activities occuring outside with no protection from weath \\
\hline See & job requires seeing \\
\hline reach & job requires reaching, handling, fingering \\
\hline Talk & job requires talking and/or hearing \\
\hline hazard & $\begin{array}{l}\text { environmental conditions on job: extreme cold or heat; wet \&/or humid; noise \&/or } \\
\text { vibration; hazards }\end{array}$ \\
\hline Svp & $\begin{array}{l}\text { specific vocational preparation for the job: short demonstration; up to } 30 \text { days; } 30 \text { days- } 3 \\
\text { mos; } 3-6 \text { mos; } 6 \text { mos- } 1 \text { yr; } 1-2 \text { yrs; } 2-4 \text { yrs; } 4-10 \text { yrs; } 10+\text { yrs }\end{array}$ \\
\hline
\end{tabular}


Table 17: Parameter estimates - model with no interactions with education.

\begin{tabular}{|c|c|c|c|c|c|}
\hline & 1970 & 1975 & 1980 & 1985 & 1990 \\
\hline Cognitive & $0.165^{* * *}$ & $0.132^{* * *}$ & 0.050 & 0.046 & $0.075^{* *}$ \\
\hline Motor & -0.002 & -0.044 & -0.035 & -0.014 & -0.025 \\
\hline Strength & 0.059 & $0.053^{*}$ & 0.012 & 0.021 & -0.001 \\
\hline People & $0.083^{*}$ & $0.063^{*}$ & -0.008 & 0.006 & -0.015 \\
\hline Cognitive*Motor & $-0.0005^{*}$ & $-0.0004^{*}$ & $-0.0003^{* *}$ & $-0.0004^{* * *}$ & $-0.0004^{* * *}$ \\
\hline Cognitive*Strength & $-0.0006^{* *}$ & $-0.0005^{* *}$ & -0.0001 & 0.0001 & -0.0001 \\
\hline Cognitive*People & $-0.0006^{* *}$ & $-0.0004^{*}$ & 0.0001 & -0.0000 & -0.0001 \\
\hline Motor*Strength & 0.0004 & $0.0005^{* * *}$ & $0.0004^{* *}$ & 0.0002 & $0.0003^{*}$ \\
\hline Motor*People & 0.0002 & $0.0003^{* *}$ & $0.0004^{* * *}$ & $0.0004^{* * *}$ & $0.0004^{* *}$ \\
\hline Strength*People & -0.0005 & $-0.0006^{* *}$ & -0.0004 & $-0.0005^{* *}$ & -0.0002 \\
\hline Age & $0.0570 * * *$ & $0.0631^{* * *}$ & $0.0660 * * *$ & $0.0888^{* * *}$ & $0.0883^{* * *}$ \\
\hline Age sqd & -0.0001 & $-0.0002^{* * *}$ & $-0.0002^{* * *}$ & $-0.0004^{* * *}$ & $-0.0004^{* * *}$ \\
\hline Experience & $-0.0185^{* * *}$ & -0.0063 & $-0.0126^{* * *}$ & $-0.0151^{* * *}$ & -0.0063 \\
\hline Exper sqd & $-0.0010^{* * *}$ & $-0.0013^{* * *}$ & $-0.0012^{* * *}$ & $-0.0014^{* * *}$ & $-0.0015^{* * *}$ \\
\hline Exper cubed & $0.0000 * * *$ & $0.0000^{* * *}$ & $0.0000 * * *$ & $0.0000 * * *$ & $0.0000^{* * *}$ \\
\hline Female & $-0.5917^{* * *}$ & $-0.5824^{* * *}$ & $-0.5572^{* * *}$ & $-0.4922^{* * *}$ & $-0.4269 * * *$ \\
\hline Black & $-0.1829 * * *$ & $-0.1096^{* * *}$ & $-0.1087^{* * *}$ & $-0.1162^{* * *}$ & $-0.0745^{* * *}$ \\
\hline Other non-white race & $-0.1769^{* * *}$ & $-0.1449 * * *$ & $-0.0753^{* * *}$ & $-0.0566 * * *$ & $-0.0804^{* * *}$ \\
\hline SMSA & $0.1571^{* * *}$ & $0.1386^{* * *}$ & $0.1104^{* * *}$ & $0.1222^{* * *}$ & $0.1395^{* * *}$ \\
\hline HS grad & -0.0201 & -0.0004 & -0.0026 & -0.0032 & $0.0902^{* * *}$ \\
\hline College grad & $0.0718^{* *}$ & 0.0142 & -0.0098 & $0.0408^{*}$ & $0.1983^{* * *}$ \\
\hline Midwest & $0.0272^{* *}$ & $0.0283^{* * *}$ & $0.0389 * * *$ & -0.0154 & $-0.0873^{* * *}$ \\
\hline South & $-0.0849 * * *$ & $-0.0691^{* * *}$ & $-0.0399 * * *$ & $-0.0195^{* *}$ & $-0.1077^{* * *}$ \\
\hline West & 0.0161 & $-0.0292^{* * *}$ & $0.0344^{* * *}$ & $0.0260 * * *$ & $-0.0655^{* * *}$ \\
\hline Constant & $-11.291^{*}$ & -6.575 & 2.542 & -0.0210 & 1.058 \\
\hline Observations & 41535 & 38876 & 61876 & 57863 & 61151 \\
\hline Adjusted R-squared & 0.43 & 0.38 & 0.36 & 0.35 & 0.35 \\
\hline
\end{tabular}

Robust standard errors in parentheses

* significant at $10 \% ; * *$ significant at $5 \% ; * * *$ significant at $1 \%$ 
Table 18: Parameter estimates - model with interactions with education.

\begin{tabular}{|c|c|c|c|c|c|}
\hline & 1970 & 1975 & 1980 & 1985 & 1990 \\
\hline \multicolumn{6}{|c|}{ Cognitive Skills } \\
\hline \multirow{2}{*}{ less than HS } & 0.12545 & 0.15755 & -0.04028 & 0.00078 & 0.01166 \\
\hline & $(0.08393)$ & $(0.06646)^{* *}$ & $(0.06037)$ & $(0.05335)$ & $(0.05296)$ \\
\hline \multirow[t]{2}{*}{ HS grad } & 0.12080 & 0.11788 & 0.07660 & 0.03984 & 0.08489 \\
\hline & $(0.04990)^{* *}$ & $(0.04626)^{* *}$ & $(0.03792)^{* *}$ & $(0.04222)$ & $(0.03976)^{* *}$ \\
\hline \multirow[t]{2}{*}{ College+ } & 0.11425 & 0.09306 & 0.01305 & -0.01251 & 0.02626 \\
\hline & $(0.05074)^{* *}$ & $(0.04182)^{* *}$ & $(0.04165)$ & $(0.04049)$ & $(0.05357)$ \\
\hline \multicolumn{6}{|c|}{ Motor Skills } \\
\hline \multirow{2}{*}{ less than HS } & 0.01575 & -0.03874 & -0.04684 & -0.10102 & -0.05199 \\
\hline & $(0.09067)$ & $(0.06467)$ & $(0.05390)$ & $(0.04534)^{* *}$ & $(0.04448)$ \\
\hline \multirow[t]{2}{*}{ HS grad } & 0.00849 & -0.01821 & -0.01454 & -0.03244 & -0.02607 \\
\hline & $(0.04700)$ & $(0.04254)$ & $(0.03112)$ & $(0.03606)$ & $(0.03128)$ \\
\hline \multirow[t]{2}{*}{ College+ } & -0.08545 & -0.09946 & -0.08537 & -0.04373 & -0.08471 \\
\hline & $(0.03718)^{* *}$ & $(0.02888)^{* * *}$ & $(0.03224)^{* * *}$ & $(0.03024)$ & $(0.04703)^{*}$ \\
\hline \multicolumn{6}{|l|}{ Strength } \\
\hline \multirow[t]{2}{*}{ less than HS } & 0.05613 & 0.02719 & -0.02651 & 0.00086 & 0.01726 \\
\hline & $(0.07065)$ & $(0.05634)$ & $(0.04478)$ & $(0.03592)$ & $(0.04357)$ \\
\hline \multirow[t]{2}{*}{ HS grad } & 0.06610 & 0.05762 & 0.01512 & 0.01670 & 0.00380 \\
\hline & $(0.03198)^{* *}$ & $(0.02895)^{* *}$ & $(0.02536)$ & $(0.02877)$ & $(0.02694)$ \\
\hline \multirow[t]{2}{*}{ College+ } & 0.09194 & 0.03812 & 0.02472 & -0.00785 & -0.06430 \\
\hline & $(0.06282)$ & $(0.04325)$ & $(0.04843)$ & $(0.04468)$ & $(0.07429)$ \\
\hline \multicolumn{6}{|c|}{ People Skills } \\
\hline \multirow[t]{2}{*}{ less than $\mathrm{HS}$} & -0.05146 & -0.03934 & -0.11820 & -0.18847 & -0.06735 \\
\hline & $(0.07572)$ & $(0.05732)$ & $(0.07380)$ & $(0.06584)^{* * *}$ & $(0.06312)$ \\
\hline \multirow[t]{2}{*}{ HS grad } & 0.03988 & 0.02933 & -0.04189 & -0.05041 & -0.04431 \\
\hline & $(0.04579)$ & $(0.04224)$ & $(0.03944)$ & $(0.04525)$ & $(0.04744)$ \\
\hline \multirow[t]{2}{*}{ College+ } & 0.23098 & 0.20491 & 0.13154 & 0.12281 & 0.09764 \\
\hline & $(0.06063)^{* * *}$ & $(0.04639)^{* * *}$ & $(0.04410)^{* * *}$ & $(0.04197)^{* * *}$ & $(0.06684)$ \\
\hline \multicolumn{6}{|c|}{ Cognitive*Motor } \\
\hline \multirow[t]{2}{*}{ less than HS } & -0.00074 & -0.00037 & -0.00039 & -0.00034 & -0.00027 \\
\hline & $(0.00050)$ & $(0.00035)$ & $(0.00025)$ & $(0.00029)$ & $(0.00026)$ \\
\hline \multirow[t]{2}{*}{ HS grad } & -0.00060 & -0.00053 & -0.00057 & -0.00041 & -0.00054 \\
\hline & $(0.00026)^{* *}$ & $(0.00023)^{* *}$ & $(0.00019)^{* * *}$ & $(0.00021)^{* *}$ & $(0.00018)^{* * *}$ \\
\hline \multirow[t]{2}{*}{ College+ } & 0.00063 & 0.00016 & 0.00017 & -0.00015 & -0.00010 \\
\hline & $(0.00031)^{* *}$ & $(0.00021)$ & $(0.00022)$ & $(0.00020)$ & $(0.00026)$ \\
\hline \multicolumn{6}{|c|}{ Cogntive*Strength } \\
\hline less than HS & -0.00088 & -0.00148 & -0.00016 & -0.00078 & -0.00041 \\
\hline & $(0.00051)^{*}$ & $(0.00035)^{* * *}$ & $(0.00037)$ & $(0.00038)^{* *}$ & $(0.00040)$ \\
\hline HS grad & -0.00043 & -0.00042 & -0.00029 & -0.00017 & -0.00019 \\
\hline & $(0.00028)$ & $(0.00027)$ & $(0.00019)$ & $(0.00023)$ & $(0.00021)$ \\
\hline College+ & -0.00013 & 0.00031 & 0.00061 & 0.00115 & 0.00092 \\
\hline & $(0.00034)$ & $(0.00025)$ & $(0.00024)^{* *}$ & $(0.00026)^{* * *}$ & $(0.00030)^{* * *}$ \\
\hline Cogniti & *People & & & & \\
\hline less than $\mathrm{HS}$ & 0.00037 & 0.00029 & 0.00098 & 0.00120 & 0.00058 \\
\hline & $(0.00036)$ & $(0.00030)$ & $(0.00040)^{* *}$ & $(0.00038)^{* * *}$ & $(0.00028)^{* *}$ \\
\hline HS grad & -0.00010 & -0.00012 & 0.00018 & 0.00031 & 0.00004 \\
\hline & $(0.00026)$ & $(0.00024)$ & $(0.00022)$ & $(0.00025)$ & $(0.00027)$ \\
\hline College+ & -0.00150 & -0.00122 & -0.00071 & -0.00065 & -0.00078 \\
\hline & $(0.00033)^{* * 2}$ & $(0.00026)^{* * *}$ & $(0.00026)^{* *}$ & $(0.00024)^{* * *}$ & $(0.00037)^{* *}$ \\
\hline
\end{tabular}


Table 18 (con`t): Parameter estimates - model with interactions with education.

\begin{tabular}{|c|c|c|c|c|c|}
\hline & 1970 & 1975 & 1980 & 1985 & 1990 \\
\hline \multicolumn{6}{|c|}{ Motor*Strength } \\
\hline \multirow[t]{2}{*}{ less than HS } & 0.00041 & 0.00094 & 0.00059 & 0.00078 & 0.00050 \\
\hline & $(0.00048)$ & $(0.00032)^{* * *}$ & $(0.00029)^{* *}$ & $(0.00027)^{* * *}$ & $(0.00030)^{*}$ \\
\hline \multirow[t]{2}{*}{ HS grad } & 0.00030 & 0.00038 & 0.00034 & 0.00031 & 0.00032 \\
\hline & $(0.00025)$ & $(0.00022)^{*}$ & $(0.00016)^{* *}$ & $(0.00020)$ & $(0.00018)^{*}$ \\
\hline \multirow[t]{2}{*}{ College+ } & 0.00001 & 0.00041 & 0.00016 & -0.00000 & 0.00039 \\
\hline & $(0.00026)$ & $(0.00022)^{*}$ & $(0.00024)$ & $(0.00022)$ & $(0.00039)$ \\
\hline \multicolumn{6}{|c|}{ Motor*People } \\
\hline \multirow[t]{2}{*}{ less than HS } & 0.00034 & -0.00005 & 0.00041 & 0.00072 & 0.00042 \\
\hline & $(0.00031)$ & $(0.00032)$ & $(0.00034)$ & $(0.00038)^{*}$ & $(0.00028)$ \\
\hline \multirow[t]{2}{*}{ HS grad } & 0.00029 & 0.00039 & 0.00046 & 0.00051 & 0.00056 \\
\hline & $(0.00016)^{*}$ & $(0.00019)^{* *}$ & $(0.00016)^{* * *}$ & $(0.00017)^{* * *}$ & $(0.00017)^{* * *}$ \\
\hline \multirow[t]{2}{*}{ College+ } & 0.00012 & 0.00040 & 0.00049 & 0.00056 & 0.00053 \\
\hline & $(0.00023)$ & $(0.00016)^{* *}$ & $(0.00017)^{* * *}$ & $(0.00016)^{* * *}$ & $(0.00024)^{* *}$ \\
\hline \multicolumn{6}{|c|}{ Strength*People } \\
\hline \multirow[t]{2}{*}{ less than HS } & -0.00018 & 0.00017 & -0.00020 & -0.00007 & -0.00032 \\
\hline & $(0.00051)$ & $(0.00048)$ & $(0.00043)$ & $(0.00041)$ & $(0.00046)$ \\
\hline \multirow[t]{2}{*}{ HS grad } & -0.00058 & -0.00058 & -0.00023 & -0.00036 & -0.00018 \\
\hline & $(0.00024)^{* *}$ & $(0.00022)^{* *}$ & $(0.00022)$ & $(0.00023)$ & $(0.00023)$ \\
\hline \multirow[t]{2}{*}{ College+ } & -0.00081 & -0.00114 & -0.00104 & -0.00112 & -0.00070 \\
\hline & $(0.00045)^{*}$ & $(0.00036)^{* * *}$ & $(0.00034)^{* * *}$ & $(0.00033)^{* * *}$ & $(0.00054)$ \\
\hline \multirow[t]{2}{*}{ Age } & 0.06077 & 0.06635 & 0.06881 & 0.08995 & 0.09223 \\
\hline & $(0.00654)^{* * *}$ & $(0.00643)^{* * *}$ & $(0.00544)^{* * *}$ & $(0.00642)^{* * *}$ & $(0.00632)^{* * *}$ \\
\hline \multirow[t]{2}{*}{ Age sqd } & -0.00012 & -0.00025 & -0.00021 & -0.00038 & -0.00045 \\
\hline & $(0.00007)^{*}$ & $(0.00006)^{* * *}$ & $(0.00006)^{* * *}$ & $(0.00007)^{* * *}$ & $(0.00007)^{* * *}$ \\
\hline \multirow[t]{2}{*}{ Experience } & -0.02196 & -0.00960 & -0.01493 & -0.01662 & -0.01028 \\
\hline & $(0.00448)^{* * *}$ & $(0.00494)^{*}$ & $(0.00417)^{* * *}$ & $(0.00469)^{* * *}$ & $(0.00473)^{* *}$ \\
\hline \multirow[t]{2}{*}{ Exper sqd } & -0.00092 & -0.00123 & -0.00120 & -0.00142 & -0.00149 \\
\hline & $(0.00012)^{* * *}$ & $(0.00014)^{* * *}$ & $(0.00013)^{* * *}$ & $(0.00014)^{* * *}$ & $(0.00014)^{* * *}$ \\
\hline \multirow[t]{2}{*}{ Exper cubed } & 0.00001 & 0.00001 & 0.00001 & 0.00002 & 0.00002 \\
\hline & $(0.00000)^{* * *}$ & $(0.00000)^{* * *}$ & $(0.00000)^{* * *}$ & $(0.00000)^{* * *}$ & $(0.00000)^{* * *}$ \\
\hline \multirow[t]{2}{*}{ Female } & -0.60226 & -0.59216 & -0.55984 & -0.50018 & -0.43270 \\
\hline & $(0.02105)^{* * *}$ & $(0.02190)^{* * *}$ & $(0.02000)^{* * *}$ & $(0.01906)^{* * *}$ & $(0.01961)^{* * *}$ \\
\hline \multirow[t]{2}{*}{ Black } & -0.17430 & -0.10752 & -0.10856 & -0.11577 & -0.07392 \\
\hline & $(0.02396)^{* * *}$ & $(0.01984)^{* * *}$ & $(0.01496)^{* * *}$ & $(0.01482)^{* * *}$ & $(0.01305)^{* * *}$ \\
\hline Other non-white race & -0.16673 & -0.14942 & -0.07398 & -0.05086 & -0.07531 \\
\hline & $(0.03862)^{* * *}$ & $(0.04138)^{* * *}$ & $(0.01940)^{* * *}$ & $(0.01740)^{* * *}$ & $(0.01623)^{* * *}$ \\
\hline SMSA & 0.15832 & 0.13950 & 0.11217 & 0.12295 & 0.14055 \\
\hline & $(0.01079)^{* * *}$ & $(0.00993)^{* * *}$ & $(0.00764)^{* * *}$ & $(0.00729)^{* * *}$ & $(0.00692)^{* * *}$ \\
\hline HS grad & -4.50760 & -4.00154 & -13.32973 & -12.90291 & -5.80396 \\
\hline & $(9.36546)$ & $(7.22141)$ & $(7.72814)^{*}$ & $(7.70164)^{*}$ & $(7.18727)$ \\
\hline College grad & -10.52501 & -7.05302 & -15.99703 & -17.33946 & -3.99368 \\
\hline & (14.41311) & (10.68767) & $(9.08703)^{*}$ & $(8.51899)^{* *}$ & (10.81187) \\
\hline Midwest & 0.02787 & 0.02933 & 0.03964 & -0.01473 & -0.08853 \\
\hline & $(0.01043)^{* * *}$ & $(0.00984)^{* * *}$ & $(0.00866)^{* * *}$ & $(0.00974)$ & $(0.00949)^{* * *}$ \\
\hline South & -0.08632 & -0.06762 & -0.03956 & -0.01960 & -0.10924 \\
\hline & $(0.00997)^{* * *}$ & $(0.00994)^{* * *}$ & $(0.00817)^{* * *}$ & $(0.00819)^{* *}$ & $(0.00795)^{* * *}$ \\
\hline West & 0.01988 & -0.02756 & 0.03690 & 0.02844 & -0.06473 \\
\hline & $(0.00985)^{* *}$ & $(0.00972)^{* * *}$ & $(0.00889)^{* * *}$ & $(0.00973)^{* * *}$ & $(0.00953)^{* * *}$ \\
\hline Constant & -3.36448 & -1.64003 & 14.99794 & 17.24854 & 7.60513 \\
\hline & (12.12098) & $(9.45851)$ & $(8.52674)^{*}$ & $(7.00669)^{* *}$ & $(6.94759)$ \\
\hline Observations & 41535 & 38876 & 61876 & 57863 & 61151 \\
\hline Adjusted R-squared & 0.44 & 0.39 & 0.37 & 0.35 & 0.35 \\
\hline
\end{tabular}


Table 19: Parameter estimates of the log-log model - model with no interactions with education.

\begin{tabular}{|c|c|c|c|c|c|}
\hline & 1970 & 1975 & 1980 & 1985 & 1990 \\
\hline Ln(Cognitive) & $\begin{array}{c}71.29931 \\
(25.14859)^{* * *}\end{array}$ & $\begin{array}{c}51.43161 \\
(18.84924)^{* * *}\end{array}$ & $\begin{array}{c}10.95997 \\
(15.06812)\end{array}$ & $\begin{array}{c}8.16904 \\
(15.17423)\end{array}$ & $\begin{array}{c}21.45327 \\
(16.01861)\end{array}$ \\
\hline Ln(Motor) & $\begin{array}{l}-1.91015 \\
(22.67407)\end{array}$ & $\begin{array}{l}-24.37651 \\
(15.62317)\end{array}$ & $\begin{array}{c}-20.31036 \\
(11.99806)^{*}\end{array}$ & $\begin{array}{c}-10.26705 \\
(11.64522)\end{array}$ & $\begin{array}{c}-14.96409 \\
(12.88801)\end{array}$ \\
\hline Ln(Strength) & $\begin{array}{c}26.55034 \\
(18.49043)\end{array}$ & $\begin{array}{c}22.28470 \\
(14.48152)\end{array}$ & $\begin{array}{c}4.30490 \\
(11.60227)\end{array}$ & $\begin{array}{c}9.35731 \\
(12.32904)\end{array}$ & $\begin{array}{c}-1.19624 \\
(15.82757)\end{array}$ \\
\hline Ln(People) & $\begin{array}{c}31.33138 \\
(21.76896)\end{array}$ & $\begin{array}{c}18.67163 \\
(15.88996)\end{array}$ & $\begin{array}{l}-13.62577 \\
(15.58944)\end{array}$ & $\begin{array}{c}-6.13450 \\
(15.46905)\end{array}$ & $\begin{array}{c}-14.81605 \\
(19.27705)\end{array}$ \\
\hline $\operatorname{Ln}($ Cognitive $) * \operatorname{Ln}($ Motor $)$ & $\begin{array}{c}-5.07224 \\
(2.81906)^{*}\end{array}$ & $\begin{array}{c}-3.57725 \\
(2.03298)^{*}\end{array}$ & $\begin{array}{c}-3.24781 \\
(1.60241)^{* *}\end{array}$ & $\begin{array}{c}-4.04283 \\
(1.61611)^{* *}\end{array}$ & $\begin{array}{c}-3.89605 \\
(1.60243)^{* *}\end{array}$ \\
\hline Ln(Cognitive) $)^{*} \operatorname{Ln}($ Strength $)$ & $\begin{array}{c}-5.60505 \\
(2.43600)^{* *}\end{array}$ & $\begin{array}{c}-4.99504 \\
(2.10414)^{* *}\end{array}$ & $\begin{array}{l}-1.01250 \\
(1.71350)\end{array}$ & $\begin{array}{c}1.04388 \\
(1.97161)\end{array}$ & $\begin{array}{l}-1.00816 \\
(1.86471)\end{array}$ \\
\hline Ln(Cognitive) $)^{*} \operatorname{Ln}($ People $)$ & $\begin{array}{l}-4.69949 \\
(3.21869)\end{array}$ & $\begin{array}{l}-2.40578 \\
(2.11075)\end{array}$ & $\begin{array}{c}2.09594 \\
(2.14564)\end{array}$ & $\begin{array}{c}1.52754 \\
(2.07083)\end{array}$ & $\begin{array}{c}0.60453 \\
(2.51777)\end{array}$ \\
\hline $\operatorname{Ln}(\text { Motor })^{*} \operatorname{Ln}($ Strength $)$ & $\begin{array}{c}3.73289 \\
(2.50322)\end{array}$ & $\begin{array}{c}5.35849 \\
(1.86448)^{* * *}\end{array}$ & $\begin{array}{c}3.50762 \\
(1.44170)^{* *}\end{array}$ & $\begin{array}{c}1.76741 \\
(1.59298)\end{array}$ & $\begin{array}{c}2.98047 \\
(1.80194)^{*}\end{array}$ \\
\hline Ln(Motor)*Ln(People) & $\begin{array}{c}1.92860 \\
(2.18191)\end{array}$ & $\begin{array}{c}3.66415 \\
(1.64902)^{* *}\end{array}$ & $\begin{array}{c}4.31401 \\
(1.61967)^{* * *}\end{array}$ & $\begin{array}{c}4.63762 \\
(1.56437)^{* * *}\end{array}$ & $\begin{array}{c}4.27771 \\
(1.96463)^{* *}\end{array}$ \\
\hline Ln $($ Strength $) * \operatorname{Ln}($ People $)$ & $\begin{array}{l}-3.99110 \\
(3.02675)\end{array}$ & $\begin{array}{c}-5.29501 \\
(2.54386)^{* *}\end{array}$ & $\begin{array}{l}-3.47596 \\
(2.33525)\end{array}$ & $\begin{array}{c}-4.91492 \\
(2.51841)^{*}\end{array}$ & $\begin{array}{l}-1.73051 \\
(3.21715)\end{array}$ \\
\hline Age & $\begin{array}{c}0.05670 \\
(0.00693)^{* * *}\end{array}$ & $\begin{array}{c}0.06286 \\
(0.00669)^{* * *}\end{array}$ & $\begin{array}{c}0.06610 \\
(0.00551)^{* * *}\end{array}$ & $\begin{array}{c}0.08867 \\
(0.00642)^{* * *}\end{array}$ & $\begin{array}{c}0.08849 \\
(0.00638)^{* * *}\end{array}$ \\
\hline Age sqd & $\begin{array}{l}-0.00008 \\
(0.00008)\end{array}$ & $\begin{array}{c}-0.00022 \\
(0.00006)^{* * *}\end{array}$ & $\begin{array}{c}-0.00019 \\
(0.00006)^{* * *}\end{array}$ & $\begin{array}{c}-0.00038 \\
(0.00007)^{* * *}\end{array}$ & $\begin{array}{c}-0.00044 \\
(0.00007)^{* * *}\end{array}$ \\
\hline Experience & $\begin{array}{c}-0.01821 \\
(0.00501)^{* * *}\end{array}$ & $\begin{array}{l}-0.00603 \\
(0.00526)\end{array}$ & $\begin{array}{c}-0.01265 \\
(0.00430)^{* * *}\end{array}$ & $\begin{array}{c}-0.01502 \\
(0.00474)^{* * *}\end{array}$ & $\begin{array}{l}-0.00646 \\
(0.00472)\end{array}$ \\
\hline Exper sqd & $\begin{array}{c}-0.00099 \\
(0.00013) * * *\end{array}$ & $\begin{array}{c}-0.00130 \\
(0.00014)^{* * *}\end{array}$ & $\begin{array}{c}-0.00123 \\
(0.00013)^{* * *}\end{array}$ & $\begin{array}{c}-0.00144 \\
(0.00014)^{* * *}\end{array}$ & $\begin{array}{c}-0.00154 \\
(0.00014)^{* * *}\end{array}$ \\
\hline Exper cubed & $\begin{array}{c}1.0 \mathrm{E}-05 \\
(0.00000)^{* * *}\end{array}$ & $\begin{array}{c}1.0 \mathrm{E}-05 \\
(0.00000)^{* * *}\end{array}$ & $\begin{array}{c}1.0 \mathrm{E}-05 \\
(0.00000)^{* * *}\end{array}$ & $\begin{array}{c}2.0 \mathrm{E}-05 \\
(0.00000)^{* * *}\end{array}$ & $\begin{array}{c}2.0 \mathrm{E}-05 \\
(0.00000)^{* * *}\end{array}$ \\
\hline Female & $\begin{array}{c}-0.59155 \\
(0.02876)^{* * *}\end{array}$ & $\begin{array}{c}-0.58320 \\
(0.02671)^{* * *}\end{array}$ & $\begin{array}{c}-0.55883 \\
(0.02103)^{* * *}\end{array}$ & $\begin{array}{c}-0.49391 \\
(0.02000)^{* * *}\end{array}$ & $\begin{array}{c}-0.42798 \\
(0.02045)^{* * *}\end{array}$ \\
\hline Black & $\begin{array}{c}-0.18364 \\
(0.02629)^{* * *}\end{array}$ & $\begin{array}{c}-0.10982 \\
(0.02109)^{* * *}\end{array}$ & $\begin{array}{c}-0.10898 \\
(0.01519)^{* * *}\end{array}$ & $\begin{array}{c}-0.11637 \\
(0.01512)^{* * *}\end{array}$ & $\begin{array}{c}-0.07488 \\
(0.01321)^{* * *}\end{array}$ \\
\hline Other non-white race & $\begin{array}{c}-0.17880 \\
(0.03928) * * *\end{array}$ & $\begin{array}{c}-0.14534 \\
(0.04259) * * *\end{array}$ & $\begin{array}{c}-0.07557 \\
(0.01942)^{* * *}\end{array}$ & $\begin{array}{c}-0.05670 \\
(0.01756)^{* * *}\end{array}$ & $\begin{array}{c}-0.08054 \\
(0.01679)^{* * *}\end{array}$ \\
\hline SMSA & $\begin{array}{c}0.15821 \\
(0.01160)^{* * *}\end{array}$ & $\begin{array}{c}0.13949 \\
(0.01064)^{* * *}\end{array}$ & $\begin{array}{c}0.11097 \\
(0.00779)^{* * *}\end{array}$ & $\begin{array}{c}0.12278 \\
(0.00743)^{* * *}\end{array}$ & $\begin{array}{c}0.13999 \\
(0.00700)^{* * *}\end{array}$ \\
\hline HS grad & $\begin{array}{l}-0.01747 \\
(0.01314)\end{array}$ & $\begin{array}{c}0.00279 \\
(0.01369)\end{array}$ & $\begin{array}{l}-0.00113 \\
(0.01247)\end{array}$ & $\begin{array}{l}-0.00086 \\
(0.01663)\end{array}$ & $\begin{array}{c}0.09156 \\
(0.01552)^{* * *}\end{array}$ \\
\hline College grad & $\begin{array}{c}0.07426 \\
(0.03625)^{* *}\end{array}$ & $\begin{array}{c}0.01740 \\
(0.02455)\end{array}$ & $\begin{array}{l}-0.01030 \\
(0.02175)\end{array}$ & $\begin{array}{c}0.04213 \\
(0.02418)^{*}\end{array}$ & $\begin{array}{c}0.19878 \\
(0.02301)^{* * *}\end{array}$ \\
\hline Midwest & $\begin{array}{c}0.02723 \\
(0.01068)^{* *}\end{array}$ & $\begin{array}{c}0.02830 \\
(0.00998)^{* * *}\end{array}$ & $\begin{array}{c}0.03878 \\
(0.00871)^{* * *}\end{array}$ & $\begin{array}{l}-0.01551 \\
(0.00978)\end{array}$ & $\begin{array}{c}-0.08748 \\
(0.00945)^{* * *}\end{array}$ \\
\hline South & $\begin{array}{c}-0.08447 \\
(0.01019) * * *\end{array}$ & $\begin{array}{c}-0.06861 \\
(0.01010)^{* * *}\end{array}$ & $\begin{array}{c}-0.03996 \\
(0.00830)^{* * *}\end{array}$ & $\begin{array}{c}-0.01944 \\
(0.00821)^{* *}\end{array}$ & $\begin{array}{c}-0.10780 \\
(0.00799)^{* * *}\end{array}$ \\
\hline West & $\begin{array}{c}0.01671 \\
(0.01015)^{*}\end{array}$ & $\begin{array}{c}-0.02863 \\
(0.00993)^{* * *}\end{array}$ & $\begin{array}{c}0.03480 \\
(0.00904)^{* * *}\end{array}$ & $\begin{array}{c}0.02654 \\
(0.00988)^{* * *}\end{array}$ & $\begin{array}{c}-0.06551 \\
(0.00959)^{* * *}\end{array}$ \\
\hline Constant & $\begin{array}{c}-290.86003 \\
(149.93819)^{*}\end{array}$ & $\begin{array}{l}-155.10411 \\
(107.03398)\end{array}$ & $\begin{array}{c}43.91306 \\
(79.98303) \\
\end{array}$ & $\begin{array}{c}-1.88804 \\
(77.92659) \\
\end{array}$ & $\begin{array}{c}21.43822 \\
(95.12780)\end{array}$ \\
\hline Observations & 41535 & 38876 & 61876 & 57863 & 61151 \\
\hline Adjusted R-squared & 0.43 & 580.38 & 0.36 & 0.35 & 0.35 \\
\hline
\end{tabular}

Robust standard errors in parentheses

* significant at $10 \%$; $* *$ significant at $5 \%$; *** significant at $1 \%$ 
Table 20: Parameter estimates of the log-log model - model with interactions with education.

\begin{tabular}{|c|c|c|c|c|c|}
\hline & 1970 & 1975 & 1980 & 1985 & 1990 \\
\hline \multicolumn{6}{|c|}{ Ln(Cognitive Skills) } \\
\hline \multirow[t]{2}{*}{ less than HS } & 44.52047 & 57.81256 & -35.85846 & -19.79497 & -7.27533 \\
\hline & $(38.52612)$ & $(30.13356)^{*}$ & $(27.25812)$ & $(23.85972)$ & $(24.79873)$ \\
\hline \multirow[t]{2}{*}{ HS grad } & 44.86010 & 41.17749 & 21.39845 & 2.18920 & 22.80586 \\
\hline & $(23.75316)^{*}$ & $(22.13529)^{*}$ & $(18.12533)$ & $(20.36670)$ & $(19.57096)$ \\
\hline \multirow[t]{2}{*}{ College+ } & 57.26237 & 39.69292 & -5.03991 & -17.30482 & 3.29886 \\
\hline & $(26.50538)^{* *}$ & $(21.88394)^{*}$ & $(21.35920)$ & $(20.91707)$ & $(27.31249)$ \\
\hline \multicolumn{6}{|c|}{ Ln(Motor Skills) } \\
\hline \multirow{2}{*}{ less than HS } & 5.02998 & -23.06959 & -29.78302 & -54.46572 & -27.96058 \\
\hline & $(40.19354)$ & $(29.84546)$ & $(24.26020)$ & $(20.33778)^{* * *}$ & $(21.04000)$ \\
\hline \multirow[t]{2}{*}{ HS grad } & 1.63551 & -12.87109 & -11.96573 & -19.24366 & -18.34636 \\
\hline & $(20.95370)$ & $(19.47422)$ & $(14.21638)$ & $(16.64733)$ & $(14.73601)$ \\
\hline \multirow[t]{2}{*}{ College+ } & -43.46602 & -49.94178 & -43.74499 & -22.90561 & -39.95402 \\
\hline & $(17.85330)^{* *}$ & $(13.89331)^{* * *}$ & $(15.40616)^{* * *}$ & $(14.75612)$ & $(22.61418)^{*}$ \\
\hline \multicolumn{6}{|c|}{ Ln(Strength) } \\
\hline \multirow[t]{2}{*}{ ess than HS } & 25.62772 & 10.54764 & -16.47574 & -1.26319 & 7.96371 \\
\hline & $(34.72078)$ & $(27.16719)$ & $(21.52140)$ & $(17.58114)$ & $(21.40755)$ \\
\hline \multirow[t]{2}{*}{ HS grad } & 28.27114 & 23.62772 & 5.60483 & 6.99553 & 1.17461 \\
\hline & $(15.04454)^{*}$ & $(13.65464)^{*}$ & $(11.83695)$ & $(13.60311)$ & $(12.95114)$ \\
\hline \multirow[t]{2}{*}{ College+ } & 45.47649 & 20.95971 & 12.08655 & -1.31933 & -26.58359 \\
\hline & $(28.77370)$ & $(20.46542)$ & $(22.89664)$ & $(21.70367)$ & $(34.67160)$ \\
\hline \multicolumn{6}{|c|}{ Ln(People Skills) } \\
\hline \multirow[t]{2}{*}{ less than HS } & -27.66265 & -21.78659 & -62.53369 & -89.15680 & -31.62579 \\
\hline & $(37.35130)$ & $(26.38030)$ & $(33.39726)^{*}$ & $(30.13648)^{* * *}$ & $(29.30130)$ \\
\hline \multirow[t]{2}{*}{ HS grad } & 7.76967 & 2.02575 & -26.47087 & -30.65379 & -26.83481 \\
\hline & $(21.11752)$ & $(19.40414)$ & $(18.58168)$ & $(21.80910)$ & $(22.91247)$ \\
\hline \multirow[t]{2}{*}{ College+ } & 116.83263 & 94.36252 & 55.08958 & 53.43713 & 42.26312 \\
\hline & $(30.32174)^{* * *}$ & $(23.37578)^{* * *}$ & $(21.30507)^{* * *}$ & $(20.93883)^{* *}$ & $(32.25458)$ \\
\hline \multicolumn{6}{|c|}{ Ln(Cognitive) ${ }^{*} \operatorname{Ln}($ Motor $)$} \\
\hline \multirow[t]{2}{*}{ less than HS } & -6.56744 & -2.64970 & -2.66792 & -1.90828 & -1.65815 \\
\hline & $(4.71494)$ & $(3.41543)$ & $(2.46441)$ & $(2.91081)$ & $(2.73506)$ \\
\hline \multirow[t]{2}{*}{ HS grad } & -6.07151 & -5.20327 & -5.25254 & -3.72803 & -4.76637 \\
\hline & $(2.56162)^{* *}$ & $(2.23948)^{* *}$ & $(1.90095)^{* * *}$ & $(2.13994)^{*}$ & $(1.83369)^{* * *}$ \\
\hline \multirow[t]{2}{*}{ College+ } & 7.82863 & 2.60960 & 2.44626 & -1.13214 & -0.66278 \\
\hline & $(3.07128)^{* *}$ & $(2.25676)$ & $(2.40425)$ & $(2.27326)$ & $(2.85136)$ \\
\hline \multicolumn{6}{|c|}{ Ln(Cogntive)*Ln(Strength) } \\
\hline less than HS & -8.14267 & -14.08850 & -1.23806 & -7.22159 & -3.58916 \\
\hline & $(4.70499)^{*}$ & $(3.49259)^{* * *}$ & $(3.49396)$ & $(3.65855)^{* *}$ & $(3.80320)$ \\
\hline HS grad & -4.09067 & -4.01367 & -2.52599 & -1.31121 & -1.72839 \\
\hline & $(2.49161)$ & $(2.44065)$ & $(1.85715)$ & $(2.24628)$ & $(1.98333)$ \\
\hline College+ & -2.25614 & 2.40408 & 6.04188 & 11.71391 & 8.77294 \\
\hline & $(3.44507)$ & $(2.59135)$ & $(2.30522)^{* * *}$ & $(2.58044)^{* * *}$ & $(2.93605)^{* * *}$ \\
\hline 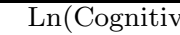 & ${ }^{* \operatorname{Ln}(\text { People })}$ & & & & \\
\hline less than HS & 5.08408 & 4.24697 & 11.76716 & 13.65123 & 6.85963 \\
\hline & $(4.00081)$ & $(3.05868)$ & $(3.87264)^{* * *}$ & $(3.78630)^{* * *}$ & $(2.95808)^{* *}$ \\
\hline HS grad & 0.60628 & 0.51577 & 3.32619 & 4.84825 & 1.87996 \\
\hline & $(2.75562)$ & $(2.49624)$ & $(2.41264)$ & $(2.74147)^{*}$ & $(2.95130)$ \\
\hline College+ & -17.68094 & -13.23454 & -6.95315 & -6.29745 & -8.13189 \\
\hline & $(4.02692)^{* * *}$ & $(3.11720)^{* * *}$ & $(2.95138)^{* *}$ & $(2.86396)^{* *}$ & $(4.22629)^{*}$ \\
\hline
\end{tabular}


Table 20 (con't): Parameter estimates of the log-log model - model with interactions with education.

\begin{tabular}{|c|c|c|c|c|c|}
\hline & 1970 & 1975 & 1980 & 1985 & 1990 \\
\hline \multicolumn{6}{|c|}{ Ln(Motor)*Ln(Strength) } \\
\hline \multirow[t]{2}{*}{ less than HS } & 3.63485 & 9.52365 & 6.17807 & 7.89336 & 4.86331 \\
\hline & $(4.71614)$ & $(3.37032)^{* * *}$ & $(2.81602)^{* *}$ & $(2.76266)^{* * *}$ & $(3.01574)$ \\
\hline \multirow[t]{2}{*}{ HS grad } & 3.01723 & 3.96340 & 3.46065 & 3.04309 & 3.24026 \\
\hline & $(2.30978)$ & $(2.08622)^{*}$ & $(1.62183)^{* *}$ & $(1.92842)$ & $(1.79122)^{*}$ \\
\hline \multirow[t]{2}{*}{ College+ } & 0.58865 & 4.10983 & 1.57754 & -0.10914 & 3.58948 \\
\hline & $(2.50893)$ & $(2.16262)^{*}$ & $(2.39203)$ & $(2.28923)$ & $(3.82068)$ \\
\hline \multicolumn{6}{|c|}{ Ln(Motor $)^{*} \operatorname{Ln}($ People $)$} \\
\hline \multirow[t]{2}{*}{ less than HS } & 2.20954 & -1.54779 & 3.26724 & 6.18835 & 3.16151 \\
\hline & $(3.22597)$ & $(3.37075)$ & $(3.48321)$ & $(4.05603)$ & $(3.12626)$ \\
\hline \multirow{2}{*}{ HS grad } & 2.87470 & 4.17257 & 4.58567 & 5.05126 & 5.67947 \\
\hline & $(1.69847)^{*}$ & $(1.99302)^{* *}$ & $(1.74675)^{* * *}$ & $(1.90249)^{* * *}$ & $(1.86424)^{* * *}$ \\
\hline \multirow[t]{2}{*}{ College+ } & 0.80813 & 4.07770 & 5.38991 & 6.14299 & 5.65118 \\
\hline & $(2.45622)$ & $(1.84839)^{* *}$ & $(2.06182)^{* * *}$ & $(1.94797)^{* * *}$ & $(2.89466)^{*}$ \\
\hline \multicolumn{6}{|c|}{ Ln $($ Strength $) * \operatorname{Ln}($ People $)$} \\
\hline \multirow[t]{2}{*}{ less than HS } & -1.24615 & 2.09469 & -1.42858 & -0.53827 & -3.13738 \\
\hline & $(5.44596)$ & $(4.85877)$ & $(4.42797)$ & $(4.20540)$ & $(4.69469)$ \\
\hline \multirow[t]{2}{*}{ HS grad } & -5.16822 & -5.16199 & -2.19788 & -3.34416 & -1.79998 \\
\hline & $(2.35489)^{* *}$ & $(2.18062)^{* *}$ & $(2.13140)$ & $(2.35339)$ & $\overline{(2.36312)}$ \\
\hline \multirow[t]{2}{*}{ College+ } & -8.21377 & -11.12603 & -10.30335 & -11.42987 & -6.63751 \\
\hline & $(4.55861)^{*}$ & $(3.80385)^{* * *}$ & $(3.50189)^{* * *}$ & $(3.62485)^{* * *}$ & $(5.67452)$ \\
\hline \multirow[t]{2}{*}{ Age } & 0.06109 & 0.06645 & 0.06884 & 0.08978 & 0.09226 \\
\hline & $(0.00652)^{* * *}$ & $(0.00643)^{* * *}$ & $(0.00542)^{* * *}$ & $(0.00641)^{* * *}$ & $(0.00628)^{* * *}$ \\
\hline \multirow[t]{2}{*}{ Age sqd } & -0.00012 & -0.00025 & -0.00021 & -0.00038 & -0.00046 \\
\hline & $(0.00007)^{*}$ & $(0.00006)^{* * *}$ & $(0.00006)^{* * *}$ & $(0.00007)^{* * *}$ & $(0.00007)^{* * *}$ \\
\hline \multirow[t]{2}{*}{ Experience } & -0.02223 & -0.00967 & -0.01497 & -0.01648 & -0.01033 \\
\hline & $(0.00450)^{* * *}$ & $(0.00498)^{*}$ & $(0.00417)^{* * *}$ & $(0.00469)^{* * *}$ & $(0.00471)^{* *}$ \\
\hline \multirow[t]{2}{*}{ Exper sqd } & -0.00092 & -0.00123 & -0.00120 & -0.00142 & -0.00149 \\
\hline & $(0.00012)^{* * *}$ & $(0.00014)^{* * *}$ & $(0.00013)^{* * *}$ & $(0.00014)^{* * *}$ & $(0.00014)^{* * *}$ \\
\hline \multirow[t]{2}{*}{ Exper cubed } & 0.00001 & 0.00001 & 0.00001 & 0.00002 & 0.00002 \\
\hline & $(0.00000)^{* * *}$ & $(0.00000)^{* * *}$ & $(0.00000)^{* * *}$ & $(0.00000)^{* * *}$ & $(0.00000)^{* * *}$ \\
\hline \multirow[t]{2}{*}{ Female } & -0.60372 & -0.59137 & -0.55999 & -0.50077 & -0.43275 \\
\hline & $(0.02045)^{* * *}$ & $(0.02212)^{* * *}$ & $(0.02019)^{* * *}$ & $(0.01917)^{* * *}$ & $(0.01976)^{* * *}$ \\
\hline \multirow[t]{2}{*}{ Black } & -0.17363 & -0.10728 & -0.10853 & -0.11578 & -0.07404 \\
\hline & $(0.02348)^{* * *}$ & $(0.01972)^{* * *}$ & $(0.01488)^{* * *}$ & $(0.01475)^{* * *}$ & $(0.01300)^{* * *}$ \\
\hline Other non-white race & -0.16626 & -0.14956 & -0.07406 & -0.05074 & -0.07506 \\
\hline & $(0.03868)^{* * *}$ & $(0.04132)^{* * *}$ & $(0.01942)^{* * *}$ & $(0.01742)^{* * *}$ & $(0.01621)^{* * *}$ \\
\hline SMSA & 0.15894 & 0.14000 & 0.11232 & 0.12313 & 0.14066 \\
\hline & $(0.01092)^{* * *}$ & $(0.01004)^{* * *}$ & $(0.00764)^{* * *}$ & $(0.00728)^{* * *}$ & $(0.00691)^{* * *}$ \\
\hline HS grad & -80.57797 & -70.06149 & -306.32481 & -284.42494 & -88.73339 \\
\hline & $(202.37710)$ & $(153.92211)$ & $(166.55573)^{*}$ & $(163.82910)^{*}$ & $(165.90461)$ \\
\hline College grad & -297.39077 & -190.25748 & -375.92387 & -406.45704 & -91.37176 \\
\hline & $(311.41724)$ & $(228.73684)$ & $(197.45488)^{*}$ & $(186.56065)^{* *}$ & $(238.75831)$ \\
\hline Midwest & 0.02797 & 0.02912 & 0.03965 & -0.01474 & -0.08867 \\
\hline & $(0.01049)^{* * *}$ & $(0.00981)^{* * *}$ & $(0.00864)^{* * *}$ & $(0.00971)$ & $(0.00947)^{* * *}$ \\
\hline South & -0.08597 & -0.06747 & -0.03970 & -0.01954 & -0.10937 \\
\hline & $(0.00991)^{* * *}$ & $(0.00994)^{* * *}$ & $(0.00817)^{* * *}$ & $(0.00819)^{* *}$ & $(0.00795)^{* * *}$ \\
\hline West & 0.02048 & -0.02752 & 0.03682 & 0.02869 & -0.06480 \\
\hline & $(0.00983)^{* *}$ & $(0.00972)^{* * *}$ & $(0.00890)^{* * *}$ & $(0.00972)^{* * *}$ & $(0.00952)^{* * *}$ \\
\hline Constant & -107.73292 & -52.68841 & 333.50793 & 378.88221 & 136.90163 \\
\hline & $(260.47605)$ & $(198.41880)$ & $(180.28900)^{*}$ & $(147.97421)^{* *}$ & $(155.63655)$ \\
\hline Observations & 41535 & 38876 & 61876 & 57863 & 61151 \\
\hline Adjusted R-squared & 0.44 & 0.39 & 0.37 & 0.35 & 0.35 \\
\hline
\end{tabular}

